\title{
Relationships between Psychological Factors and Experimental Pain Outcomes in Healthy Individuals: Results from 8 Studies
}

Hadas Nahman-Averbuch ${ }^{1,2}$, Ian A. Boggero ${ }^{1,2,3}$, Benjamin M. Hunter ${ }^{1}$, Hannah Pickerill ${ }^{1}$, James Peugh ${ }^{1,4}$, Eric Leon ${ }^{1}$, Victor J. Schneider II ${ }^{1}$, Nichole M. Emerson ${ }^{5}$, Priya L. Thomas ${ }^{1}$, Susmita Kashikar-Zuck ${ }^{1,2,4}$, Cassidy Hughes ${ }^{1}$, Marie-Eve Hoeppli ${ }^{1,2}$, Christopher D. King ${ }^{1,2,4}$, Robert C. Coghill1,2,4

${ }^{1}$ Division of Behavioral Medicine and Clinical Psychology, Cincinnati Children's Hospital Medical Center, Cincinnati, OH, USA; ${ }^{2}$ Center for Understanding Pediatric Pain, Cincinnati Children's Hospital Medical Center, Cincinnati, OH, USA; ${ }^{3}$ Department of Oral Health Science, Division of Orofacial Pain, University of Kentucky College of Dentistry, Lexington, KY, USA ${ }^{4}$ Department of Pediatrics, University of Cincinnati College of Medicine, Cincinnati, OH, USA, ${ }^{5}$ Department of Neuroscience, Wake Forest University School of Medicine, Winston-Salem, NC, USA

Key words: Psychological Factors, Quantitative Sensory Testing, Anxiety, Depression, Pain Catastrophizing

\section{Corresponding author:}

Hadas Nahman-Averbuch, PhD

Division of Behavioral Medicine and Clinical Psychology

Cincinnati Children's Hospital Medical Center 
3333 Burnet Ave, Cincinnati, OH, 45229-3026

Tel: +1.513.636.4416, Email: $\underline{\text { Hadas.NahmanAverbuch@cchmc.org }}$

Conflict of Interest: The authors declare no conflict of interest regarding this work 


\section{Abstract}

Psychological factors, such as anxiety, depression, and pain catastrophizing, may affect how healthy individuals experience experimental pain. However, current literature puts forth contradictory results, possibly due to differing study methodologies, such as the type of psychophysical measure or survey. To better understand such results, this paper analyzed the relationships between psychological factors and experimental pain outcomes across eight different studies (total $n=595$ ) conducted in different populations of healthy adult and adolescent participants. Analyses were conducted with and without controlling for sex, age, and race. Each study was analyzed separately and as part of an aggregate analysis. Even without correction for multiple comparisons, only a few significant relationships were found for the individual studies. Controlling for demographic factors had minimal effect on the results. Importantly, even the few statistically significant models showed relatively small effect sizes; psychological factors explained no more than $20 \%$ of the variability in experimental pain sensitivity of healthy individuals. The aggregate analyses revealed relationships between anxiety and PPT / cold pain ratings and between pain catastrophizing and PPT. Sample size calculations based on the aggregate analyses indicated that several hundred participants would be required to correctly detect relationships between these psychological factors and pain measures. These overall negative findings suggest that anxiety, depression, and pain catastrophizing in healthy individuals may not be meaningfully related to experimental pain outcomes. Furthermore, positive findings in the literature may be subject to small group effects and publication bias towards positive findings. 


\section{Introduction}

Individual differences in how people experience pain are profound and may be influenced by various demographic, physiological, genetic and psychological factors. The most commonly examined psychological factors related to experimental pain outcomes are anxiety, depression and pain catastrophizing $[22,25,35,40,42,47,63$, $68,73,77,85]$. Although it is well accepted that psychological factors relate to experimental pain outcomes, contradictory results exist, especially in healthy individuals, with some studies finding significant relationships $[4,26,45]$ and others not finding such relationships $[9,31,53,65,69]$. Although it is not clear why these contradictory results exist, one explanation may be differing cross-study methodologies (psychological survey, pain stimuli, study sample).

Our laboratory has performed multiple studies where healthy participants completed psychological surveys and underwent experimental pain testing. However, the relationships between psychological factors and pain are often not explored. The goal of the current study was to focus on the relationships between psychological factors and experimental pain outcomes in healthy participants using data from eight different studies conducted by our group. These studies were conducted in different populations (adults or adolescents) using several different types of psychological surveys, which may allow us to identify patterns present only within certain surveys or populations. If such patterns exist, they could explain the inconsistent findings on the relationships between psychological parameters and experimental pain outcomes across currently published studies. Understanding these relationships is important not only for the 
identification of factors contributing to how individuals process and respond to pain but also for the development of pain interventions targeting those factors.

\section{Methods}

This manuscript includes data from eight different studies including unpublished studies, involving psychological and experimental pain outcome parameters [7, 8, 54, 57]. For psychological measures, we focused on anxiety, depression and pain catastrophizing. For experimental pain outcomes, we focused on pressure pain thresholds (PPT), conditioned pain modulation (CPM) response, cold pain tolerance, and pain intensity and unpleasantness ratings of cold-water immersion. These measures were chosen for being the most common across all the studies. The studies were analyzed separately due to minor, but potentially critical, differences between the studies. These differences allowed us to see with greater detail potentially subtle patterns in variable relationships among different populations and measures. Information about the specific studies can be found in Table 1 and Supplementary 1. In addition, aggregate analyses combining the results of all studies were conducted. Data from this study will be shared at the request of other investigators for purposes of replicating procedures and results.

\section{Participants}

All participants included in these analyses were healthy with 1) no psychiatric or neurological disorders, 2) no chronic pain diagnoses, and 3) no current pain medication use on a regular basis. Specific inclusion criteria for each of the studies are described in Supplementary 1. 


\section{Quantitative Sensory Testing (QST) measures}

Pain Ratings of Suprathreshold Pain- In all studies (except for study 8), participants were asked to indicate the magnitude of pain sensation with a visual analog scale (VAS). The VAS is a simple rating scale with ratio scale properties [60]. Participants were instructed to move a $15 \mathrm{~cm}$ hand-held slider to the right, exposing a red colored strip underneath, until the amount of red showing matched their perception of pain intensity or unpleasantness. Pain intensity (how strong the pain feels) and pain unpleasantness (how disturbing the pain is) were defined for the participant before testing began using an analogy about the volume of a radio [61]. Both intensity and unpleasantness dimensions ranged between a minimum value of 0 , meaning no pain or unpleasantness sensation, and a maximum value of 10 , meaning most intense or unpleasant sensation imaginable, and were recorded with a precision of 0.1 units. Participants were not able to see the numerical value of the ratings they gave. In study 8, participants were asked to report their perceived pain intensity using a verbal numerical pain scale ranging from 0 ("no pain"), to 10 ("worst pain imaginable").

\section{Pressure Pain Thresholds (PPT)- Pressure stimulation (AlgoMed -}

Computerized Pressure Algometer, Medoc, Ramat Yishai, Israel) was gradually increased until the participant felt a sensation of pain. The participant was instructed to press a hand-held button as soon as they first felt a painful sensation, which was used to indicate their pain thresholds. The force of the pressure at the time of the button push 
was recorded. This procedure was repeated two or three times. Details on PPT locations for each study can be found in Table 1.

Conditioned Pain Modulation (CPM)_CPM is based on a "pain-inhibits-pain" concept that represents a spatial filtering mechanism [55]. In the CPM paradigm, one noxious stimulus (i.e., conditioning stimulus) inhibits the pain intensity of another noxious stimulus (i.e., test stimulus) that is delivered to a remote area of the body [1]. The CPM response is defined as a reduction in the perceived magnitude of pain from the test stimulus when it is delivered alone versus when it is delivered concurrently with the conditioning stimulus. An inhibitory CPM response is represented by negative values. We included all paradigms in the cases in which more than one CPM paradigm was collected. Details of the differing methods of assessing CPM are included in Table 1. Cold pain tolerance- Participants immersed their hand or foot in a cold-water bath (temperature range for studies $0-4^{\circ} \mathrm{C}$, Table 1). Pain tolerance was defined by the time of limb withdrawal (seconds). Pain ratings of cold pain intensity and pain unpleasantness were collected upon limb withdrawal (see next section).

Pain ratings of cold-water immersion- Participants were asked to rate their perception of pain intensity and unpleasantness with a VAS during or following hand/foot immersion into cold water. In some studies, this stimulus of cold-water immersion served as the conditioning stimulus of the CPM paradigm, while in others it was used to assess coldpain tolerance. If several cold-water immersions were applied in the same study using identical stimulus parameters, only the first immersion was included in the analysis.

\section{Psychological surveys}


Each of the eight studies included one or more of the widely used surveys described below, assessing anxiety, depression or pain catastrophizing (Table 1). Adult versions were used for participants ages 18-44. Adolescent versions were used for participants ages 14-17.

Anxiety-

1. The Patient-Reported Outcomes Measurement Information System (PROMIS $®$ ) Anxiety questionnaire $[11,12]$ has 8 items assessing fear, uneasiness, and hyperarousal over the past 7 days. Both the adult and pediatric version use a scale from "Never" (1) to "Always" or "Almost Always" (5). Scores are summed across all items, with higher scores indicating greater anxiety. The pediatric version of this measure uses age-appropriate wording (i.e., "I felt worried" vs. "I felt anxious") and has specifically been validated in pediatric populations.

2. The Spielberger State Trait Anxiety Inventory (STAI)- The STAI has participants selfreport perceived anxiety at the state (temporary) and trait (enduring, stable) levels. Both the state and trait subscales consist of 20 items scored on a scale ranging from "Almost Never" (1) to "Almost Always" (4) [70]. For the current study, only trait anxiety was examined to reduce the number of comparisons and for a better comparison with the other anxiety surveys.

Depression-

1. The PROMIS Depression questionnaire $[11,12]$ has 8 items assessing depressive symptoms such as negative mood, anhedonia, negative views of self, and negative social cognition over the past seven days. Each question has five response options with 
a range between 1-5. Scores are summed across all items, with higher scores indicating greater depressive symptoms.

2. Beck Depression Inventory (BDI)- The BDI is a widely used self-report survey that measures characteristic attitudes and symptoms of depression. The BDI has 21-items, each scored on a scale between 0 to 3 . Anchors for each score are written next to the score for each question. The scores are summed for a total score of level of depression. Score of <10 indicate normal state, 11-16 mild mood disturbance, 17-20 borderline clinical depression, 21-30 moderate depression, 31-40 severe depression, >40 extreme depression [6].

\section{Pain Catastrophizing-}

Pain Catastrophizing Scale (PCS)- Pain catastrophizing is defined as a tendency to mentally aggrandize pain experiences. The PCS contains 13 items representing the 3 components of rumination, magnification, and helplessness; a total score represents overall levels of pain catastrophizing. Each item is rated on a scale ranging from "Not at All" (0) to "All the Time" (4). Participants completed the questionnaire referring to previous pain events. The total score of pain catastrophizing was calculated [74].

\section{Statistical analysis}

For each study, we first computed descriptive statistics for all available psychological and experimental pain variables. Next, we ran separate linear regressions using each psychological variable as a predictor of each experimental pain variable. After computing all univariate models between psychological variables and experimental pain outcomes, we reran all models with the covariates of age, sex, and race 
simultaneously. These models allowed us to test whether psychological variables were related to pain outcomes above and beyond the effects due to age, sex, or race. A separate dummy code (0/1) variable was created for each racial category (Asian, Black, Other, Mixed) for each study, with White serving as the reference group. If a study did not include any participants from a particular racial group, the dummy code for that group was not included in the analyses. All statistics were run with SPSS Version 25.

Additional aggregate analyses combining the results of all studies were conducted using R statistical software [76], the R meta-analysis package "metafor" [82], and R-Studio were employed for the meta-analyses [67]. While these aggregate analyses were conducted in a similar way to a meta-analysis, they are not formal meta-analyses, as since they are derived from these studies of our group alone rather than an assessment of the published literature. Aggregate analyses were performed only in cases of at least three studies for a specific analysis. Aggregate analyses employed Fisher's ztransformation, as conventionally done for meta-analyses. DerSimonian and Laird's random-effects model was used for determining relationships [16]. These analyses were performed only in cases of at least three studies for a specific analysis. The aggregate analyses were conducted on the data that was not controlled for sex, age and race to better mimic common analyses of across studies in which controlling for demographic variables is usually not possible.

For aggregate analyses that were significant or trending towards significance $(p<0.1)$, a sample size calculation for future studies was conducted based on the grand mean 
results found in the aggregate analyses. Sample calculations were conducted using $G^{*}$ Power (version 3.1.9.7) [20] and used alpha of 0.05 and power of 0.80 .

\section{Results}

Study (1)

Twenty regression models were tested for this study (adolescents, $n=58$ ). A significant positive relationship was found between both anxiety / depression levels and pain intensity / pain unpleasantness ratings of foot immersion into cold water. This indicates that greater anxiety and depression were each associated with greater pain sensitivity, demonstrated by higher ratings of cold pain intensity and unpleasantness. No significant associations were found between anxiety / depression and the QST data of PPT / the two CPM responses (using heat or PPT as the test stimulus). After controlling for sex, age, and race, the associations between pain intensity / pain unpleasantness ratings of cold water and anxiety / depression remained significant. None of the other associations were significant (Table 2).

\section{Study (2)}

Sixteen regression models were tested for this study (adolescents, $n=20$ ). No associations were found between the psychological factors of anxiety and depression and the QST measures of PPT, CPM response, and pain intensity and unpleasantness of cold-water immersion. These results remained unchanged after controlling for sex, age, and race of the participants (Table 3).

\section{Study (3)}


Thirty-six regression models were tested for this study (adolescents, $n=33$ ). No associations were found between the psychological factors of anxiety, depression and pain catastrophizing and any of the QST measures (PPT tested at the trapezius and at the forearm, pain intensity and unpleasantness ratings of cold-water immersion and the two CPM responses). No associations were found even after controlling for sex, age, and race (Table 4).

Study (4)

Sixteen regression models were tested for this study (adults and adolescents, $n=31$ ). A significant association was found between anxiety and CPM. No other associations were found between anxiety and depression and cold pain tolerance, pain intensity or pain unpleasantness ratings of cold-water immersion). After controlling for sex, age, and race, the association between anxiety and CPM was no longer significant. However, the association between anxiety and cold pain tolerance, which was not significant, was significant after controlling for the demographic factors (Table 5).

\section{Study (5)}

Twenty-four regression models were tested for this study (adults and adolescents, $\mathrm{n}=122$ ). Significant associations were found between anxiety and both pain intensity and pain unpleasantness ratings of cold-water immersion. There were no significant associations between anxiety and CPM or cold pain tolerance, and none of the pain measures were associated with depression or pain catastrophizing. After controlling for sex, age, and race the association between anxiety and pain intensity and pain unpleasantness ratings of cold-water immersion remained significant (Table 6). 
Study (6)

Six regression models were tested for this study (adults, $n=21$ ). No associations were found between the psychological factors of anxiety, depression and pain catastrophizing and PPT in healthy adults. These results were not changed when we controlled for sex, age and race of the participants (Table 7).

\section{Study (7)}

Twelve regression models were tested for this study (adults, $n=84$ ). No associations were found between the psychological factors of anxiety and depression and the QST measures of cold tolerance (time, pain intensity and pain unpleasantness). These results were not changed when we controlled for sex, age and race of the participants (Table 8).

Study (8)

Six regression models were tested for this study (adults, $n=226$ ). No associations were found between pain catastrophizing and the QST measures of PPT, CPM, and pain intensity of cold-water immersion. These results were not changed when we controlled for sex, age and race of the participants (Table 9).

\section{Aggregate analyses across studies}

There was no evidence for significant associations between anxiety and CPM response or cold pain tolerance across studies (Figure 1, Table 10). However, a significant association was found between anxiety and PPT (Fisher's z $-0.10[-0.19,-0.01])$ as well as between anxiety and cold pain intensity (Fisher's z 0.18 [0.04, 0.32]). A nonsignificant trend towards a relationship between anxiety and cold pain unpleasantness 
was also noted. Given the small effect sizes of these relationships, sample size calculation indicated that for future prospective studies 767 participants would be required in order to correctly detect the association between anxiety and PPT. To correctly detect the association between anxiety and cold pain intensity, 237 participants would be required. In addition, to correctly detect the association between anxiety and cold pain unpleasantness, a sample size of 297 participants would be required.

There was also no evidence for significant association between depression and any of the pain sensitivity measures across studies, although a non-significant trend towards a relationship between depression and cold pain unpleasantness was noted (Figure 1, Table 10). Sample size calculation indicated that for future studies, 647 participants would be required to correctly detect the association between depression and cold pain unpleasantness.

Across studies, PPT was the only pain sensitivity measure found to be related to pain catastrophizing (Fisher's z -0.14 [-0.26, -0.02]); however, there was no evidence for significant association between pain catastrophizing and CPM or cold pain intensity (Figure 1, Table 10). Sample size calculation indicated that 399 participants would be required to correctly detect the association between pain catastrophizing and PPT.

\section{Discussion}

Few associations were found between psychological factors and experimental pain outcomes within each of the eight studies. This overall lack of associations was determined even without any corrections for multiple comparisons. Across all studies, 
136 regression models were conducted with an alpha value of 0.05 . Without corrections for multiple comparisons, and simply by chance, approximately 7 results should be significant. We found that 8 models were significant without controlling for multiple comparisons. Thus, these positive findings are close to the number that would be predicted by chance and may not represent real effects. Even when statistically significant associations were found, the maximum explained variability remained less than $20 \%$. In most cases, controlling for demographic factors such as sex, age and race did not change the results. Thus, demographic factors may have a small effect on the relationships between psychological factors and experimental pain sensitivity.

The aggregate analyses integrated the results of the individual studies across hundreds of participants and found small, yet statistically significant relationships between anxiety and PPT and anxiety and cold pain intensity as well as between pain catastrophizing and PPT. The significance of these findings is questionable given the small effect sizes detected. The sample size calculation, which was based on the aggregate analyses, indicated that in order to correctly detect associations between these psychological factors and pain measures, the minimum number of participants would range from approximately 240 to 760 participants. Thus, positive findings of associations between psychological factors and experimental pain measures in healthy participants may be subject to small group effects and publication bias towards positive findings. Although several associations were significant, the majority of our findings were negative. These overall negative findings are important because they challenge conventional wisdom 
that psychological factors in healthy individuals are associated with experimental pain outcomes.

\section{Anxiety}

In the aggregate analyses, higher anxiety levels were related to higher pain sensitivity of lower PPT and higher cold pain intensity ratings. It is not clear why anxiety would be related only to these experimental pain measures. A previous meta-analysis also found that anxiety was related only to CPM paradigm that used PPT as the test stimulus and cold pain as the conditioning stimulus [56], which may suggest that anxiety has greater influence on these pain measures.

Within the individual studies, anxiety was associated with pain sensitivity in two out of six studies, but without corrections for multiple comparisons. The difference between one study that found a significant association and the studies that did not may be partially due to the type of anxiety survey that was used. The PROMIS survey was used in study 5 that found an association while STAI was used in studies 4 and 7 which did not find associations. The STAI reflects more general distress or negative affect and the PROMIS Anxiety assesses more of the specific symptoms of fearfulness/anxiety [2]. Thus, in healthy individuals, the PROMIS survey measures may be more related to pain perception in that people who are generally more worried and fearful are the ones reporting pain as being more unpleasant and intense. 


\section{Pain Catastrophizing}

Pain catastrophizing measures people's tendency to magnify or ruminate over real or imagined pain experiences. In the present investigation, pain catastrophizing was not correlated with PPT, CPM, cold pain tolerance, or pain intensity and unpleasantness of cold-water immersion in any of the three studies in which it was tested. However, aggregate analysis across these studies found a relationship between higher pain catastrophizing and lower PPT (greater pain sensitivity). It is not clear why PPT would be the only parameter related to pain catastrophizing. One possibility is that PPT was the only threshold measure examined across studies and that individuals with higher tendencies to catastrophize mislabeled innocuous sensations as painful. Across all three studies, the PCS was used to assess pain catastrophizing. Other surveys that assess different aspects of pain catastrophizing, such as the Coping Strategies Questionnaire (CSQ) [66], might have revealed different relationships with experimental pain in healthy individuals.

\section{Depression}

No significant associations between depression and any of the pain measures were found in the aggregate analysis across studies. Significant associations between depression and pain intensity and unpleasantness of cold-water immersion in healthy adolescents were found in only one study, and in light of the aggregate analyses, may represent a false positive. Similar to anxiety surveys, there are several surveys that assess depression which differ in some parameters. The PROMIS depression scale is a narrower and more precise measure of mood and has participants rate the 
frequency/duration of those symptoms in the past 7 days, whereas the $\mathrm{BDI}$ is a multidimensional measure which assess various aspects including sleep, appetite, and self-worth. Participants are asked to report the intensity of their symptoms. The BDI is more diagnostically aligned with clinical symptoms of depression [75].

\section{Factors contributing to weak associations in healthy individuals vs patients}

The overall lack of associations that were found in the individual studies between anxiety, depression and pain catastrophizing and experimental pain sensitivity may be surprising. Various studies have shown significant relationships between anxiety, depression and pain catastrophizing, and levels of clinical pain and experimental pain sensitivity in pain patients [10, 24, 37, 38, 42, 43, 68, 83]. However, psychological factors may affect pain differently in healthy individuals and pain patients. Interestingly, pain catastrophizing predicted postoperative pain after breast surgery in patients who had chronic pain before the surgery - but not in patients without chronic pain before the surgery [68]. This emphasizes the possibility of an interaction between the influence of psychological factors on pain and the presence or absence of chronic pain. Patients with chronic pain have been found to experience higher levels of anxiety, depression and pain catastrophizing compared to healthy controls $[30,35,36,39,44,58,80]$. Conversely, several studies have shown that pain-free individuals with psychiatric disorders such as depression or post-traumatic stress disorder have reduced sensitivity to pain $[23,33,71]$. However, other studies have found no differences between the groups [72] or increased pain sensitivity in these patients [14, 15, 48]. Thus, it is possible that anxiety, depression and pain catastrophizing have only minor effects on 
pain in healthy controls, while individuals with higher levels of psychological factors or pain have interactions that can be observed.

The results of the present study are in line with the results of a previous meta-analysis that examined the relationships between CPM and psychological factors [56]. In the meta-analysis, when all studies were grouped together, no relationships were found between CPM response and psychological factors (anxiety, depression, pain catastrophizing) in both healthy and chronic pain patients. [56]. This is similar to the aggregate analysis that grouped all studies together and found no associations between any of the psychological factors and CPM. However, another meta-analysis focused only on Irritable Bowel Syndrome (IBS) patients and found that CPM responses were correlated with anxiety and pain catastrophizing [41]. Thus, the relationships between experimental pain and psychological parameters may be specific to chronic pain patients or a sub-group of patients, to pain measures, or to psychological factors.

Controlling for sex, age, and race had minimal effect on the results. This may indicate that although demographic factors can affect both pain and psychological measures, they may not be involved in the relationships between psychological factors and experimental pain sensitivity in healthy individuals. Sex, age, and race differences in pain are well characterized in previous literature $[3,5,9,21,27,34,45,46,49,64,79]$. In addition, sex, age, and race can affect levels of anxiety, depression and pain catastrophizing $[9,21,45,50-52]$. Several studies found that sex can affect the relationships between psychological factors and pain sensitivity, with different relationships reported for men and women $[78,79]$. However, another study did not find 
this relationship [50]. Since controlling for sex, age, and race had a minimal effect on the results, we suggest that it may not be necessary to control for these factors in future studies assessing the relationships between psychological and experimental pain in healthy participants.

\section{Conclusions}

Although the common notion is that psychological factors affect experimental pain sensitivity, we found only a few associations between these factors in healthy participants. Furthermore, relatively high numbers of healthy participants would be required to find these associations due to their small effect sizes. These findings have two important implications for the design of future studies of healthy participants. First, these results raise the possibility of small group effects where positive relationships are found by chance despite lacking an adequate sample of the population. In future studies where such relationships are of interest, relatively large numbers of participants should be recruited to ensure an experiment will be adequately powered to detect these small effects. Second, in psychologically healthy individuals for whom these variables contribute minimally to individual differences in pain, the time and effort needed to obtain this data in detail may be avoided. Instead, rapidly administered screening tools could be implemented to ensure that key factors like anxiety and depression fall within healthy ranges. 


\section{Acknowledgments}

Study 1 was funded by the Cincinnati Children's' Hospital Medical Center (CCHMC) Arnold W. Strauss Fellow Award (HNA). Study 2 was funded by startup funds (RCC and CDK). Study 3 was funded by CCHMC Cincinnati Children's Research Innovation/Pilot Funding Program (RIP) Award (CDK). Studies 4 and 5 were funded by a NIH/NINDS (R01NS085391, RCC)) grant. Study 6 was funded by a NIH/NIDCR (R00DE022368, CDK). Study 7 was funded by NIH/NINDS (R01NS039426 RCC). We thank Suzanne Segerstrom, Ph.D., M.P.H. (University of Kentucky) for her contribution to the study design and mentored investigator on data collection.

\section{References}

[1] Arendt-Nielsen L and Yarnitsky D. Experimental and clinical applications of quantitative sensory testing applied to skin, muscles and viscera. The journal of pain : official journal of the American Pain Society 2009;10(6):556-572.

[2] Bados A, Gomez-Benito J and Balaguer G. The state-trait anxiety inventory, trait version: does it really measure anxiety? Journal of personality assessment 2010;92(6):560-567.

[3] Bagwath Persad LA, Kamerman PR and Wadley AL. Predictors of Cold and Pressure Pain Tolerance in Healthy South African Adults. Pain medicine (Malden, Mass) 2017;18(11):2126-2137.

[4] Bakshi N, Lukombo I, Shnol H, Belfer I and Krishnamurti L. Psychological Characteristics and Pain Frequency Are Associated With Experimental Pain Sensitivity 
in Pediatric Patients With Sickle Cell Disease. The journal of pain : official journal of the American Pain Society 2017;18(10):1216-1228.

[5] Bartley EJ and Fillingim RB. Sex differences in pain: a brief review of clinical and experimental findings. British journal of anaesthesia 2013;111(1):52-58.

[6] Beck AT, Ward CH, Mendelson M, Mock J and Erbaugh J. An inventory for measuring depression. Archives of general psychiatry 1961;4:561-571.

[7] Boggero IA, Schneider VJ, 2nd, Thomas PL, Nahman-Averbuch H and King CD. Associations of self-report and actigraphy sleep measures with experimental pain outcomes in patients with temporomandibular disorder and healthy controls. Journal of psychosomatic research 2019;123:109730.

[8] Boggero IA and Segerstrom SC. Self-regulatory ability, fatigue, and the experience of pain: Mechanistic insights from pain-free undergraduates. Psychophysiology 2019;56(9):e13388.

[9] Bulls HW, Lynch MK, Petrov ME, Gossett EW, Owens MA, Terry SC, Wesson-Sides KM and Goodin BR. Depressive Symptoms and Sleep Efficiency Sequentially Mediate Racial Differences in Temporal Summation of Mechanical Pain. Annals of behavioral medicine : a publication of the Society of Behavioral Medicine 2017;51(5):673-682. [10] Campbell CM, Kronfli T, Buenaver LF, Smith MT, Berna C, Haythornthwaite JA and Edwards RR. Situational versus dispositional measurement of catastrophizing: associations with pain responses in multiple samples. The journal of pain : official journal of the American Pain Society 2010;11(5):443-453.e442.

[11] Cella D, Riley W, Stone A, Rothrock N, Reeve B, Yount S, Amtmann D, Bode R, Buysse D, Choi S, Cook K, Devellis R, DeWalt D, Fries JF, Gershon R, Hahn EA, Lai 
JS, Pilkonis P, Revicki D, Rose M, Weinfurt K and Hays R. The Patient-Reported Outcomes Measurement Information System (PROMIS) developed and tested its first wave of adult self-reported health outcome item banks: 2005-2008. Journal of clinical epidemiology 2010;63(11):1179-1194.

[12] Cella D, Yount S, Rothrock N, Gershon R, Cook K, Reeve B, Ader D, Fries JF, Bruce B and Rose M. The Patient-Reported Outcomes Measurement Information System (PROMIS): progress of an NIH Roadmap cooperative group during its first two years. Medical care 2007;45(5 Suppl 1):S3-s11.

[13] de Heer EW, Gerrits MM, Beekman AT, Dekker J, van Marwijk HW, de Waal MW, Spinhoven P, Penninx BW and van der Feltz-Cornelis CM. The association of depression and anxiety with pain: a study from NESDA. PloS one 2014;9(10):e106907. [14] Defrin R, Ginzburg K, Solomon Z, Polad E, Bloch M, Govezensky M and Schreiber S. Quantitative testing of pain perception in subjects with PTSD--implications for the mechanism of the coexistence between PTSD and chronic pain. Pain 2008;138(2):450459.

[15] Defrin R, Schreiber S and Ginzburg K. Paradoxical Pain Perception in Posttraumatic Stress Disorder: The Unique Role of Anxiety and Dissociation. The journal of pain : official journal of the American Pain Society 2015;16(10):961-970.

[16] DerSimonian R, \& Laird, N. Meta-analysis in clinical trials. Controlled Clinical Trials 1986;7:177-188.

[17] Dickens C, McGowan L and Dale S. Impact of depression on experimental pain perception: a systematic review of the literature with meta-analysis. Psychosomatic medicine 2003;65(3):369-375. 
[18] Edwards RR, Cahalan C, Mensing G, Smith M and Haythornthwaite JA. Pain, catastrophizing, and depression in the rheumatic diseases. Nature reviews Rheumatology 2011;7(4):216-224.

[19] Edwards RR, Moric M, Husfeldt B, Buvanendran A and Ivankovich O. Ethnic similarities and differences in the chronic pain experience: a comparison of african american, Hispanic, and white patients. Pain medicine (Malden, Mass) 2005;6(1):88-98. [20] Faul F, Erdfelder E, Lang AG and Buchner A. G*Power 3: a flexible statistical power analysis program for the social, behavioral, and biomedical sciences. Behav Res Methods 2007;39(2):175-191.

[21] Fillingim RB, King CD, Ribeiro-Dasilva MC, Rahim-Williams B and Riley JL, 3rd. Sex, gender, and pain: a review of recent clinical and experimental findings. The journal of pain : official journal of the American Pain Society 2009;10(5):447-485. [22] Fond G, Loundou A, Hamdani N, Boukouaci W, Dargel A, Oliveira J, Roger M, Tamouza R, Leboyer M and Boyer L. Anxiety and depression comorbidities in irritable bowel syndrome (IBS): a systematic review and meta-analysis. European archives of psychiatry and clinical neuroscience 2014;264(8):651-660.

[23] Geuze E, Westenberg HG, Jochims A, de Kloet CS, Bohus M, Vermetten E and Schmahl C. Altered pain processing in veterans with posttraumatic stress disorder. Archives of general psychiatry 2007;64(1):76-85.

[24] Giesecke T, Gracely RH, Williams DA, Geisser ME, Petzke FW and Clauw DJ. The relationship between depression, clinical pain, and experimental pain in a chronic pain cohort. Arthritis and rheumatism 2005;52(5):1577-1584. 
[25] Gorczyca R, Filip R and Walczak E. Psychological aspects of pain. Annals of agricultural and environmental medicine : AAEM 2013;Spec no. 1:23-27.

[26] Granot M, Granovsky Y, Sprecher E, Nir RR and Yarnitsky D. Contact heat-evoked temporal summation: tonic versus repetitive-phasic stimulation. Pain 2006;122(3):295305.

[27] Grashorn W, Sprenger C, Forkmann K, Wrobel N and Bingel U. Age-dependent decline of endogenous pain control: exploring the effect of expectation and depression. PloS one 2013;8(9):e75629.

[28] Grosen K, Vase L, Pilegaard HK, Pfeiffer-Jensen M and Drewes AM. Conditioned pain modulation and situational pain catastrophizing as preoperative predictors of pain following chest wall surgery: a prospective observational cohort study. PloS one 2014;9(2):e90185.

[29] Grundstrom H, Larsson B, Arendt-Nielsen L, Gerdle B and Kjolhede P. Pain catastrophizing is associated with pain thresholds for heat, cold and pressure in women with chronic pelvic pain. Scand J Pain 2020.

[30] Heymen S, Maixner W, Whitehead WE, Klatzkin RR, Mechlin B and Light KC.

Central processing of noxious somatic stimuli in patients with irritable bowel syndrome compared with healthy controls. The Clinical journal of pain 2010;26(2):104-109.

[31] King CD, Jastrowski Mano KE, Barnett KA, Pfeiffer M, Ting TV and Kashikar-Zuck S. Pressure Pain Threshold and Anxiety in Adolescent Females With and Without Juvenile Fibromyalgia: A Pilot Study. The Clinical journal of pain 2017;33(7):620-626. 
[32] Kjogx H, Kasch H, Zachariae R, Svensson P, Jensen TS and Vase L. Experimental manipulations of pain catastrophizing influence pain levels in patients with chronic pain and healthy volunteers. Pain 2016;157(6):1287-1296.

[33] Kraus A, Geuze E, Schmahl C, Greffrath W, Treede RD, Bohus M and Vermetten E. Differentiation of pain ratings in combat-related posttraumatic stress disorder. Pain 2009;143(3):179-185.

[34] Lautenbacher S, Peters JH, Heesen M, Scheel J and Kunz M. Age changes in pain perception: A systematic-review and meta-analysis of age effects on pain and tolerance thresholds. Neuroscience and biobehavioral reviews 2017;75:104-113.

[35] Lee C, Doo E, Choi JM, Jang SH, Ryu HS, Lee JY, Oh JH, Park JH and Kim YS. The Increased Level of Depression and Anxiety in Irritable Bowel Syndrome Patients Compared with Healthy Controls: Systematic Review and Meta-analysis. Journal of neurogastroenterology and motility 2017;23(3):349-362.

[36] Lee YC, Lu B, Edwards RR, Wasan AD, Nassikas NJ, Clauw DJ, Solomon DH and Karlson EW. The role of sleep problems in central pain processing in rheumatoid arthritis. Arthritis and rheumatism 2013;65(1):59-68.

[37] Lerman SF, Rudich Z, Brill S, Shalev H and Shahar G. Longitudinal associations between depression, anxiety, pain, and pain-related disability in chronic pain patients. Psychosomatic medicine 2015;77(3):333-341.

[38] Liu F, Fang T, Zhou F, Zhao M, Chen M, You J, Jin Y, Xie J and Liu Z. Association of Depression/Anxiety Symptoms with Neck Pain: A Systematic Review and MetaAnalysis of Literature in China. Pain research \& management 2018;2018:3259431. 
[39] López-Ruiz M, Losilla JM, Monfort J, Portell M, Gutiérrez T, Poca V, GarciaFructuoso F, Llorente J, Garcia-Fontanals A and Deus J. Central sensitization in knee osteoarthritis and fibromyalgia: Beyond depression and anxiety. PloS one 2019;14(12):e0225836.

[40] Malfliet A, Coppieters I, Van Wilgen P, Kregel J, De Pauw R, Dolphens M and Ickmans K. Brain changes associated with cognitive and emotional factors in chronic pain: A systematic review. European journal of pain (London, England) 2017;21(5):769786.

[41] Marcuzzi A, Chakiath RJ, Siddall PJ, Kellow JE, Hush JM, Jones MP, Costa DSJ and Wrigley PJ. Conditioned Pain Modulation (CPM) is Reduced in Irritable Bowel Syndrome: A Systematic Review and Meta-Analysis of CPM and the Role of Psychological Factors. Journal of clinical gastroenterology 2019;53(6):399-408. [42] Marshall PWM, Schabrun S and Knox MF. Physical activity and the mediating effect of fear, depression, anxiety, and catastrophizing on pain related disability in people with chronic low back pain. PloS one 2017;12(7):e0180788.

[43] Meints SM and Edwards RR. Evaluating psychosocial contributions to chronic pain outcomes. Progress in neuro-psychopharmacology \& biological psychiatry $2018 ; 87$ (Pt B):168-182.

[44] Meints SM, Mawla I, Napadow V, Kong J, Gerber J, Chan ST, Wasan AD, Kaptchuk TJ, McDonnell C, Carriere J, Rosen B, Gollub RL and Edwards RR. The relationship between catastrophizing and altered pain sensitivity in patients with chronic low-back pain. Pain 2019;160(4):833-843. 
[45] Meints SM, Stout M, Abplanalp S and Hirsh AT. Pain-Related Rumination, But Not Magnification or Helplessness, Mediates Race and Sex Differences in Experimental Pain. The journal of pain : official journal of the American Pain Society 2017;18(3):332339.

[46] Meints SM, Wang V and Edwards RR. Sex and Race Differences in Pain Sensitization among Patients with Chronic Low Back Pain. The journal of pain : official journal of the American Pain Society 2018;19(12):1461-1470.

[47] Miller MM, Meints SM and Hirsh AT. Catastrophizing, pain, and functional outcomes for children with chronic pain: a meta-analytic review. Pain 2018;159(12):2442-2460.

[48] Moeller-Bertram T, Strigo IA, Simmons AN, Schilling JM, Patel P and Baker DG. Evidence for acute central sensitization to prolonged experimental pain in posttraumatic stress disorder. Pain medicine (Malden, Mass) 2014;15(5):762-771.

[49] Mogil JS. Sex differences in pain and pain inhibition: multiple explanations of a controversial phenomenon. Nature reviews Neuroscience 2012;13(12):859-866.

[50] Moore DJ, Eccleston C and Keogh E. Does sex moderate the relationship between anxiety and pain? Psychology \& health 2013;28(7):746-764.

[51] Munce SE and Stewart DE. Gender differences in depression and chronic pain conditions in a national epidemiologic survey. Psychosomatics 2007;48(5):394-399. [52] Nahman-Averbuch H, Dayan L, Sprecher E, Hochberg U, Brill S, Yarnitsky D and Jacob G. Sex differences in the relationships between parasympathetic activity and pain modulation. Physiology \& behavior 2016;154:40-48. 
[53] Nahman-Averbuch H, Granovsky Y, Coghill RC, Yarnitsky D, Sprecher E and Weissman-Fogel I. Waning of "conditioned pain modulation": a novel expression of subtle pronociception in migraine. Headache 2013;53(7):1104-1115.

[54] Nahman-Averbuch H, Leon E, Hunter BM, Ding L, Hershey AD, Powers SW, King $\mathrm{CD}$ and Coghill RC. Increased pain sensitivity but normal pain modulation in adolescents with migraine. Pain 2019.

[55] Nahman-Averbuch H, Martucci KT, Granovsky Y, Weissman-Fogel I, Yarnitsky D and Coghill RC. Distinct brain mechanisms support spatial vs temporal filtering of nociceptive information. Pain 2014;155(12):2491-2501.

[56] Nahman-Averbuch H, Nir RR, Sprecher E and Yarnitsky D. Psychological Factors and Conditioned Pain Modulation: A Meta-Analysis. The Clinical journal of pain 2016;32(6):541-554 .

[57] Nahman-Averbuch H, Thomas PL, Schneider VJ, 2nd, Chamberlin LA, Peugh JL, Hershey AD, Powers SW, Coghill RC and King CD. Spatial aspects of pain modulation are not disrupted in adolescents with migraine. Headache 2020.

[58] Neuendorf R, Harding A, Stello N, Hanes D and Wahbeh H. Depression and anxiety in patients with Inflammatory Bowel Disease: A systematic review. Journal of psychosomatic research 2016;87:70-80.

[59] Picavet HS, Vlaeyen JW and Schouten JS. Pain catastrophizing and kinesiophobia: predictors of chronic low back pain. American journal of epidemiology 2002;156(11):1028-1034. 
[60] Price DD, Bush FM, Long S and Harkins SW. A comparison of pain measurement characteristics of mechanical visual analogue and simple numerical rating scales. Pain 1994;56(2):217-226.

[61] Price DD, McGrath PA, Rafii A and Buckingham B. The validation of visual analogue scales as ratio scale measures for chronic and experimental pain. Pain 1983;17(1):45-56 .

[62] Raak R and Wallin M. Thermal thresholds and catastrophizing in individuals with chronic pain after whiplash injury. Biological research for nursing 2006;8(2):138-146. [63] Racine M, Tousignant-Laflamme $Y$, Kloda LA, Dion D, Dupuis G and Choinière M. A systematic literature review of 10 years of research on sex/gender and pain perception - part 2: do biopsychosocial factors alter pain sensitivity differently in women and men? Pain 2012;153(3):619-635.

[64] Rahim-Williams B, Riley JL, 3rd, Williams AK and Fillingim RB. A quantitative review of ethnic group differences in experimental pain response: do biology, psychology, and culture matter? Pain medicine (Malden, Mass) 2012;13(4):522-540. [65] Rezaii T, Hirschberg AL, Carlstrom K and Ernberg M. The influence of menstrual phases on pain modulation in healthy women. The journal of pain : official journal of the American Pain Society 2012;13(7):646-655.

[66] Rosenstiel AK and Keefe FJ. The use of coping strategies in chronic low back pain patients: relationship to patient characteristics and current adjustment. Pain 1983;17(1):33-44 .

[67] RStudio. RStudio: Integrated development environment for R. Boston, MA. . http://wwwrstudioorg/ 2012. 
[68] Ruscheweyh R, Viehoff A, Tio J and Pogatzki-Zahn EM. Psychophysical and psychological predictors of acute pain after breast surgery differ in patients with and without pre-existing chronic pain. Pain 2017;158(6):1030-1038.

[69] Sarlani E, Grace EG, Reynolds MA and Greenspan JD. Sex differences in temporal summation of pain and aftersensations following repetitive noxious mechanical stimulation. Pain 2004;109(1-2):115-123.

[70] Spielberger CD, Gorsuch, R. L., Lushene, R., Vagg, P. R., \& Jacobs, G. A. Manual for the State-Trait Anxiety Inventory. Palo Alto, CA: Consulting Psychologists Press 1983.

[71] Strigo IA, Simmons AN, Matthews SC and Craig AD. The relationship between amygdala activation and passive exposure time to an aversive cue during a continuous performance task. PloS one 2010;5(11):e15093.

[72] Strigo IA, Simmons AN, Matthews SC, Craig AD and Paulus MP. Association of major depressive disorder with altered functional brain response during anticipation and processing of heat pain. Archives of general psychiatry 2008;65(11):1275-1284. [73] Suffeda A, Meissner W, Rosendahl J and Guntinas-Lichius O. Influence of depression, catastrophizing, anxiety, and resilience on postoperative pain at the first day after otolaryngological surgery: A prospective single center cohort observational study. Medicine 2016;95(28):e4256.

[74] Sullivan MJLB, S.; Pivik, J.;. The Pain Catastrophizing Scale: Development and validation. Psychol Assess 1995;7:524-532.

[75] Sultan S, Luminet O and Hartemann A. Cognitive and anxiety symptoms in screening for clinical depression in diabetes: a systematic examination of diagnostic 
performances of the HADS and BDI-SF. Journal of affective disorders 2010;123(13):332-336.

[76] Team tRC. R: A language and environment for statistical computing. $R$ Foundation for Statistical Computing, Vienna, Austria. URL http://wwwR-projectorg/ 2014.

[77] Theunissen M, Peters ML, Bruce J, Gramke HF and Marcus MA. Preoperative anxiety and catastrophizing: a systematic review and meta-analysis of the association with chronic postsurgical pain. The Clinical journal of pain 2012;28(9):819-841. [78] Thibodeau MA, Welch PG, Katz J and Asmundson GJ. Pain-related anxiety influences pain perception differently in men and women: a quantitative sensory test across thermal pain modalities. Pain 2013;154(3):419-426.

[79] Thompson T, Keogh E, French CC and Davis R. Anxiety sensitivity and pain: generalisability across noxious stimuli. Pain 2008;134(1-2):187-196.

[80] Tran MT, Arendt-Nielsen L, Kupers R and Elberling J. Multiple chemical sensitivity: on the scent of central sensitization. International journal of hygiene and environmental health 2013;216(2):202-210.

[81] Vangronsveld K, Van Damme S, Peters M, Vlaeyen J, Goossens M and Crombez G. An experimental investigation on attentional interference by threatening fixations of the neck in patients with chronic whiplash syndrome. Pain 2007;127(1-2):121-128. [82] Viechtbauer W. Conducting meta-analyses in $\mathrm{R}$ with the metafor package. Journal of Statistical Software 2010;36(3):1-48. 
[83] Vissers MM, Bussmann JB, Verhaar JA, Busschbach JJ, Bierma-Zeinstra SM and Reijman M. Psychological factors affecting the outcome of total hip and knee arthroplasty: a systematic review. Seminars in arthritis and rheumatism 2012;41(4):576588.

[84] Wallin M, Liedberg G, Borsbo B and Gerdle B. Thermal detection and pain thresholds but not pressure pain thresholds are correlated with psychological factors in women with chronic whiplash-associated pain. The Clinical journal of pain 2012;28(3):211-221 .

[85] Wood TJ, Thornley P, Petruccelli D, Kabali C, Winemaker M and de Beer J. Preoperative Predictors of Pain Catastrophizing, Anxiety, and Depression in Patients Undergoing Total Joint Arthroplasty. The Journal of arthroplasty 2016;31(12):27502756. 
Figure legends

Figure 1. Aggregate analyses across studies.

Aggregate analyses were performed only in cases of at least three studies for a specific analysis. The aggregate analyses were conducted on the data that was not controlled for sex, age and race to better mimic common analyses of across studies in which controlling for demographic variables is usually not possible. Significant correlation was found between anxiety and PPT, anxiety and cold pain intensity and between pain catastrophizing and PPT. 
Table 1- Description of Demographic, QST, and Psychological Measures for Studies Included in the Analysis

\begin{tabular}{|c|c|c|c|c|c|c|c|c|c|c|c|}
\hline \multirow{3}{*}{ 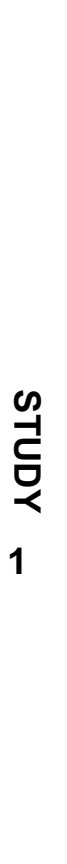 } & \multicolumn{6}{|c|}{$\begin{array}{c}\text { QST PARAMETERS } \\
\text { (Location, Intensity, Duration - if } \\
\text { appliable) }\end{array}$} & \multicolumn{5}{|c|}{$\begin{array}{l}\text { PSYCHOLOGICAL } \\
\text { PARAMETERS }^{c}\end{array}$} \\
\hline & 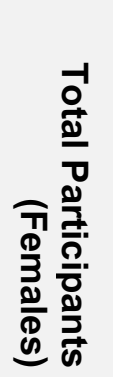 & 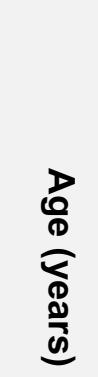 & 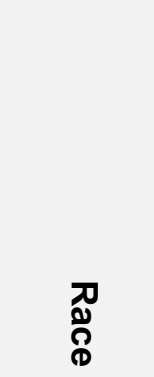 & 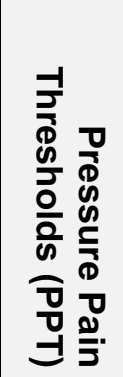 & 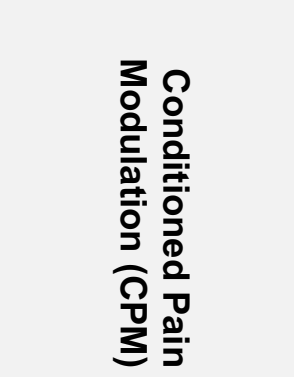 & 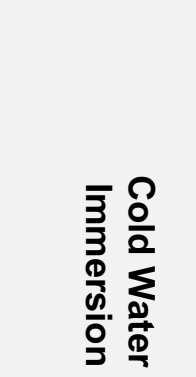 & 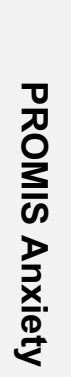 & 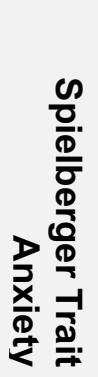 & 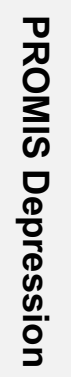 & 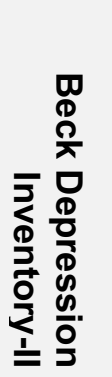 & 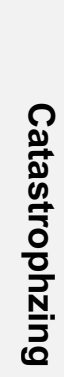 \\
\hline & $\begin{array}{l}58 \\
(38)\end{array}$ & $\begin{array}{r}14.2 \\
\pm 1.7\end{array}$ & $\begin{array}{l}\text { White: } \\
43 \\
\text { Black: } \\
15 \\
\text { Asian: } 0 \\
\text { Other: } 0\end{array}$ & LG & $\begin{array}{l}\frac{T S \# 1: \text { PPT (LG) }}{T S \text { \#2: Heat }} \\
\text { stimuli }\left(46^{\circ} \mathrm{C},\right. \\
\text { 30s, LG) } \\
\text { CS: Foot } \\
\text { immersion }\left(8^{\circ} \mathrm{C} \text {, }\right. \\
60 \mathrm{~s})\end{array}$ & $\begin{array}{l}\text { Int \& Unp } \\
\text { (Foot, } 8^{\circ} \mathrm{C} \\
60 \mathrm{~s})^{b}\end{array}$ & $P$ & - & $P$ & - & - \\
\hline 2 & $\begin{array}{l}20 \\
(16)\end{array}$ & $\begin{array}{l}13.8 \\
\pm 2.5\end{array}$ & $\begin{array}{l}\text { White: } \\
14 \\
\text { Black: } 3 \\
\text { Asian: } 0 \\
\text { Other: } 3\end{array}$ & Trap & $\begin{array}{l}\text { TS: PPT (Trap) } \\
\text { IS: Foot } \\
\text { immersion }\left(8^{\circ} \mathrm{C} \text {, }\right. \\
60 \mathrm{~s})\end{array}$ & $\begin{array}{l}\text { Int \& Unp } \\
\text { (Foot, } 8^{\circ} \mathrm{C} \\
60 \mathrm{~s})^{b}\end{array}$ & $P$ & - & $P$ & - & - \\
\hline 3 & $\begin{array}{l}33 \\
(30)\end{array}$ & $\begin{array}{r}15.5 \\
\pm 1.4\end{array}$ & $\begin{array}{l}\text { White: } \\
29 \\
\text { Black: } 3 \\
\text { Asian: } 0 \\
\text { Other: } 2\end{array}$ & $\begin{array}{l}\text { Trap } \\
\text { FA }\end{array}$ & $\begin{array}{l}\frac{T S \# 1:}{\text { (Trap) }} \\
\text { PPT \#2: PPT (FA) } \\
\frac{\text { CS: Hand }}{\text { immersion }\left(10^{\circ} \mathrm{C} \text {, }\right.} \\
60 \mathrm{~s})\end{array}$ & $\begin{array}{l}\text { Int \& Unp } \\
\text { (Hand, } \\
\left.10^{\circ} \mathrm{C}, 60 \mathrm{~s}\right)\end{array}$ & $P$ & - & $\mathrm{P}$ & - & $P$ \\
\hline $4^{a}$ & $\begin{array}{l}31 \\
(12)\end{array}$ & $\begin{array}{l}28.7 \\
\pm 7.4\end{array}$ & $\begin{array}{l}\text { White: } \\
21 \\
\text { Black: } 7 \\
\text { Asian: } 3 \\
\text { Other: } 0\end{array}$ & - & $\begin{array}{l}\frac{T S}{{ }^{\circ}} \text { : Heat stimuli } \\
\left.{ }^{\circ} \mathrm{C}, 30 \mathrm{~s}, \mathrm{FA}\right) \\
\frac{\mathrm{CS}}{\mathrm{imm}} \text { Foot } \\
60 \mathrm{~s})\end{array}$ & $\begin{array}{l}\text { CPTo Int, } \\
\& \text { Unp } \\
\left(4^{\circ} \mathrm{C}, \max \right. \\
120 \text { s })\end{array}$ & - & $\frac{A}{P}$ & - & $\frac{A}{P}$ & - \\
\hline $5^{a}$ & $\begin{array}{l}122 \\
(83)\end{array}$ & $\begin{array}{l}27.9 \\
\pm 6.8\end{array}$ & $\begin{array}{l}\text { White: } \\
104 \\
\text { Black: } \\
22 \\
\text { Asian: } 5 \\
\text { Other: } 0\end{array}$ & - & 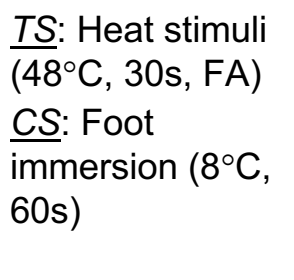 & $\begin{array}{l}\text { CPTo Int, } \\
\& \text { Unp } \\
\text { (Hand, } \\
4^{\circ} \mathrm{C}, \max \\
120 \mathrm{~s})\end{array}$ & $\frac{A}{P}$ & - & $\frac{A}{P}$ & - & $\frac{A}{P}$ \\
\hline 6 & $\begin{array}{l}21 \\
(17)\end{array}$ & $\begin{array}{l}27.8 \\
\pm 7.2\end{array}$ & $\begin{array}{l}\text { White: } \\
13 \\
\text { Black: } 3\end{array}$ & FA & - & - & $A$ & - & $A$ & - & A \\
\hline
\end{tabular}




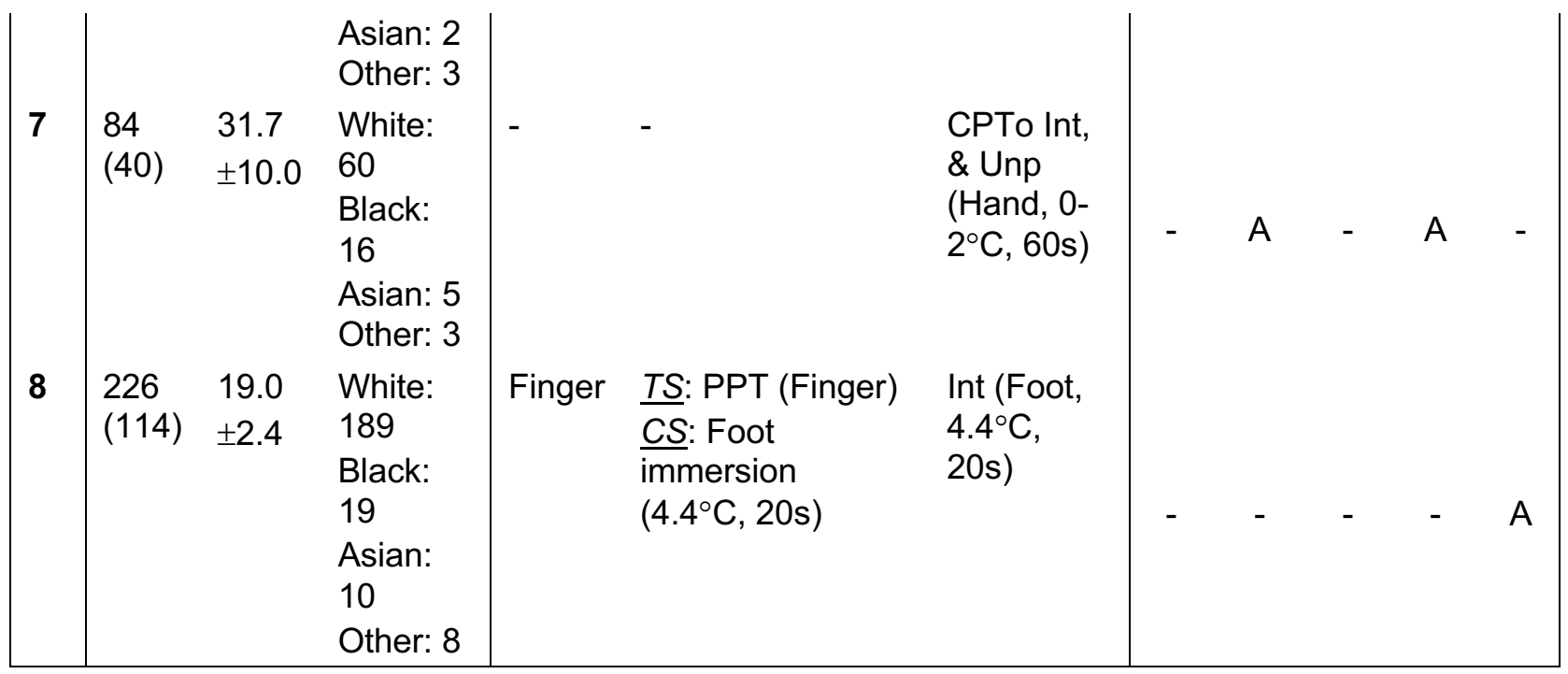

\section{Notes}

${ }^{a}$ Both adults and adolescents were included

${ }^{b}$ Pain ratings of conditioning stimulus (CS) during CPM

${ }^{c}$ Completed with either adult $(A)$ and pediatric $(P)$ measures

\section{Abbreviations}

Conditioned Pain Modulation: TS, Testing Stimulus; CS, Conditioning Stimulus Cold Immersion: CPTo, Cold Pain Tolerance; Int, Cold Pain Intensity; Unp, Cold Pain Unpleasantness.

Anatomical locations: LG, Lower leg; Trap, Trapezius; FA, Forearm; F 
Table 2. Relationships between psychological factors and experimental pain sensitivity with and without controlling for demographic factors- Results of Study \#1

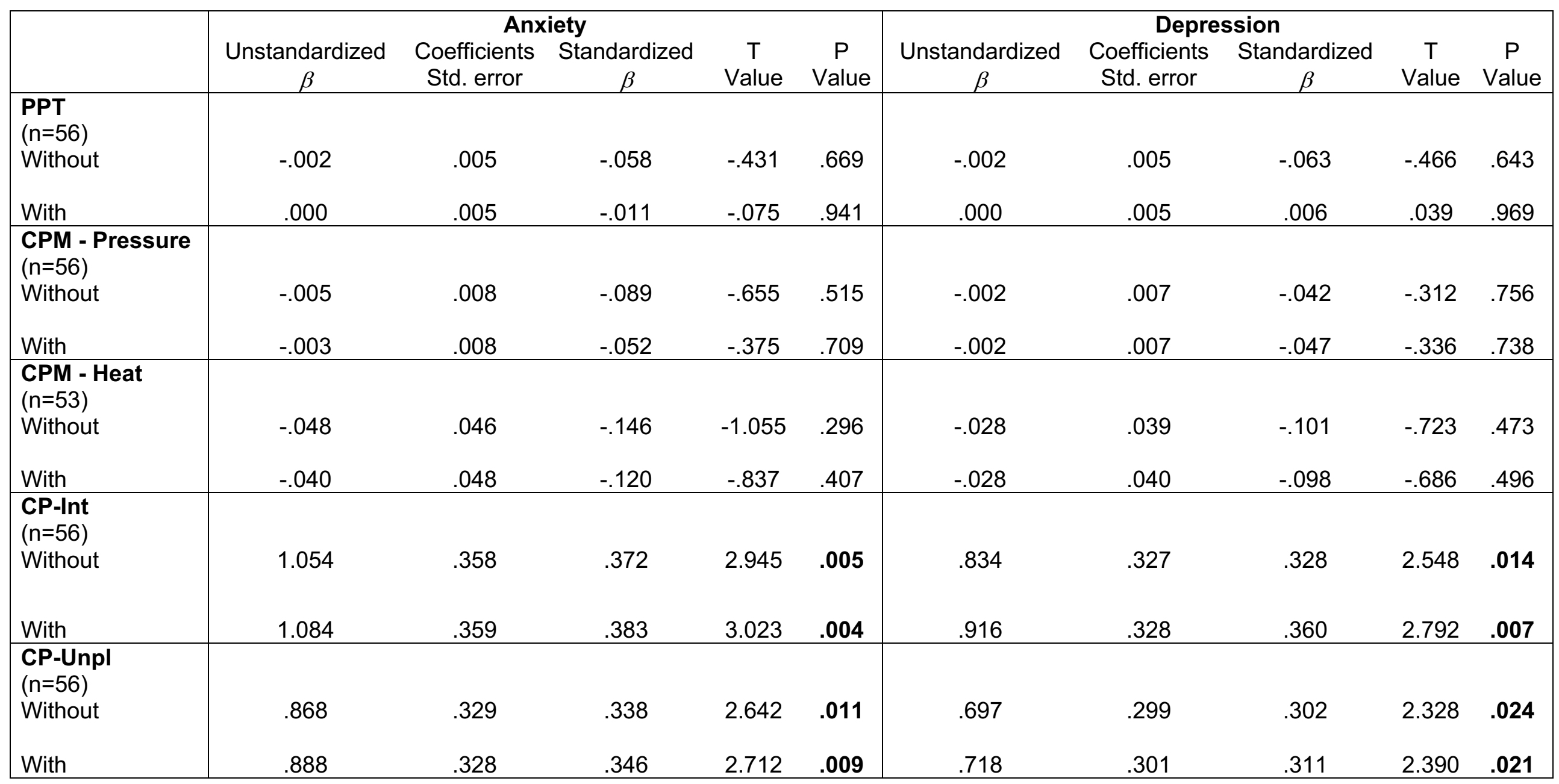

PPT, Pressure Pain Thresholds; CPM, Conditioned Pain Modulation Response; CP-Int, Cold Pain Intensity Ratings; CP-Unpl, Cold Pain Unpleasantness Ratings. 
Table 3. Relationships between psychological factors and experimental pain sensitivity with and without controlling for demographic factors- Results of Study \#2

\begin{tabular}{|c|c|c|c|c|c|c|c|c|c|c|}
\hline & \multirow[b]{2}{*}{$\begin{array}{c}\text { Unstandardized } \\
\beta\end{array}$} & \multicolumn{4}{|c|}{ Anxiety } & \multicolumn{5}{|c|}{ Depression } \\
\hline & & $\begin{array}{l}\text { Coefficients } \\
\text { Std. error }\end{array}$ & $\begin{array}{c}\text { Standardized } \\
\beta\end{array}$ & $\begin{array}{c}\mathrm{T} \\
\text { Value }\end{array}$ & $\begin{array}{c}P \\
\text { Value }\end{array}$ & $\begin{array}{c}\text { Unstandardiz } \\
\text { ed } \beta\end{array}$ & $\begin{array}{c}\text { Coefficients } \\
\text { Std. error }\end{array}$ & $\begin{array}{c}\text { Standardized } \\
\beta\end{array}$ & $\begin{array}{c}\mathrm{T} \\
\text { Value }\end{array}$ & $\begin{array}{c}P \\
\text { Value }\end{array}$ \\
\hline $\begin{array}{l}\text { PPT } \\
(n=20)\end{array}$ & & & & & & & & & & \\
\hline Without & -.001 & .005 & -.039 & -.164 & .872 & -.002 & .003 & -.141 & -.604 & .554 \\
\hline With & .001 & .006 & .062 & .224 & .826 & -.004 & .004 & -.292 & -.968 & .348 \\
\hline $\begin{array}{l}\text { CPM } \\
(n=20)\end{array}$ & & & & & & & & & & \\
\hline Without & .006 & .010 & .129 & .552 & .588 & .000 & .006 & .007 & .030 & .997 \\
\hline With & .007 & .010 & .162 & .708 & .490 & -.001 & .006 & -.035 & -.135 & .894 \\
\hline $\begin{array}{l}\text { CP-Int } \\
(n=20) \\
\text { Without }\end{array}$ & .030 & .354 & .020 & .085 & .933 & .148 & .199 & .173 & .744 & .467 \\
\hline With & -.112 & .351 & -.075 & -.320 & .753 & .104 & .224 & .121 & .463 & .650 \\
\hline $\begin{array}{l}\text { CP_Unp } \\
(n=20) \\
\text { Without }\end{array}$ & -.210 & .255 & -.190 & -.823 & .421 & .018 & .148 & .029 & .121 & .905 \\
\hline With & -.303 & .252 & -.275 & -1.205 & .247 & .013 & .169 & .021 & .078 & .939 \\
\hline
\end{tabular}

PPT, Pressure Pain Thresholds; CPM, Conditioned Pain Modulation response; CP-Int, Cold Pain Intensity Ratings; CP-Unpl, Cold Pain Unpleasantness Ratings. 
Table 5. Relationships between psychological factors and experimental pain sensitivity with and without controlling for demographic factors- Results of Study \#4

\begin{tabular}{|c|c|c|c|c|c|c|c|c|c|c|}
\hline & & & Anxiety & & & & Dep & ession & & \\
\hline & $\begin{array}{c}\text { Unstandardized } \\
\beta\end{array}$ & $\begin{array}{l}\text { Coefficients } \\
\text { Std. error }\end{array}$ & $\begin{array}{c}\text { Standardized } \\
\beta\end{array}$ & $\begin{array}{c}\text { T } \\
\text { Value }\end{array}$ & $\begin{array}{c}\mathrm{P} \\
\text { Value }\end{array}$ & $\begin{array}{c}\text { Unstandardized } \\
\beta\end{array}$ & $\begin{array}{l}\text { Coefficients } \\
\text { Std. error }\end{array}$ & $\begin{array}{c}\text { Standardized } \\
\beta\end{array}$ & $\begin{array}{c}\text { T } \\
\text { Value }\end{array}$ & $\begin{array}{c}P \\
\text { Value }\end{array}$ \\
\hline $\begin{array}{l}\text { CPM } \\
(n=26)\end{array}$ & & & & & & & & & & \\
\hline Without & -.070 & .031 & -.422 & -2.281 & .032 & -.086 & .064 & -.264 & -1.339 & .193 \\
\hline With & -.075 & .039 & -.453 & -1.917 & .070 & -.017 & .070 & -.052 & -.241 & .812 \\
\hline $\begin{array}{l}\text { CP } \\
\text { Tolerance } \\
(n=31) \\
\text { Without }\end{array}$ & .018 & .012 & .261 & 1.459 & .155 & -.010 & .024 & -.077 & -.415 & .681 \\
\hline With & .028 & .014 & .413 & 2.067 & .049 & -.030 & .024 & -.232 & -1.254 & .222 \\
\hline $\begin{array}{l}\text { CP-Int } \\
(n=31) \\
\text { Without }\end{array}$ & .223 & .226 & .180 & .988 & .331 & -.328 & .440 & -.137 & -.744 & .463 \\
\hline With & .263 & .257 & .212 & 1.023 & .316 & -.198 & .446 & -.083 & -.444 & .661 \\
\hline $\begin{array}{l}\text { CP-Unpl } \\
(n=31) \\
\text { Without }\end{array}$ & .292 & .214 & .245 & 1.364 & .183 & -.043 & .427 & -.019 & -.100 & .921 \\
\hline With & .332 & .256 & .279 & 1.298 & .206 & .065 & .451 & .028 & .144 & .887 \\
\hline
\end{tabular}

CPM, Conditioned Pain Modulation Response; CP Tolerance, Cold Pain Tolerance; CP-Int, Cold Pain Intensity Ratings; CP-Unpl, Cold Pain Unpleasantness Ratings. 
Table 6. Relationships between psychological factors and experimental pain sensitivity with and without controlling for demographic factors- Results of Study \#5

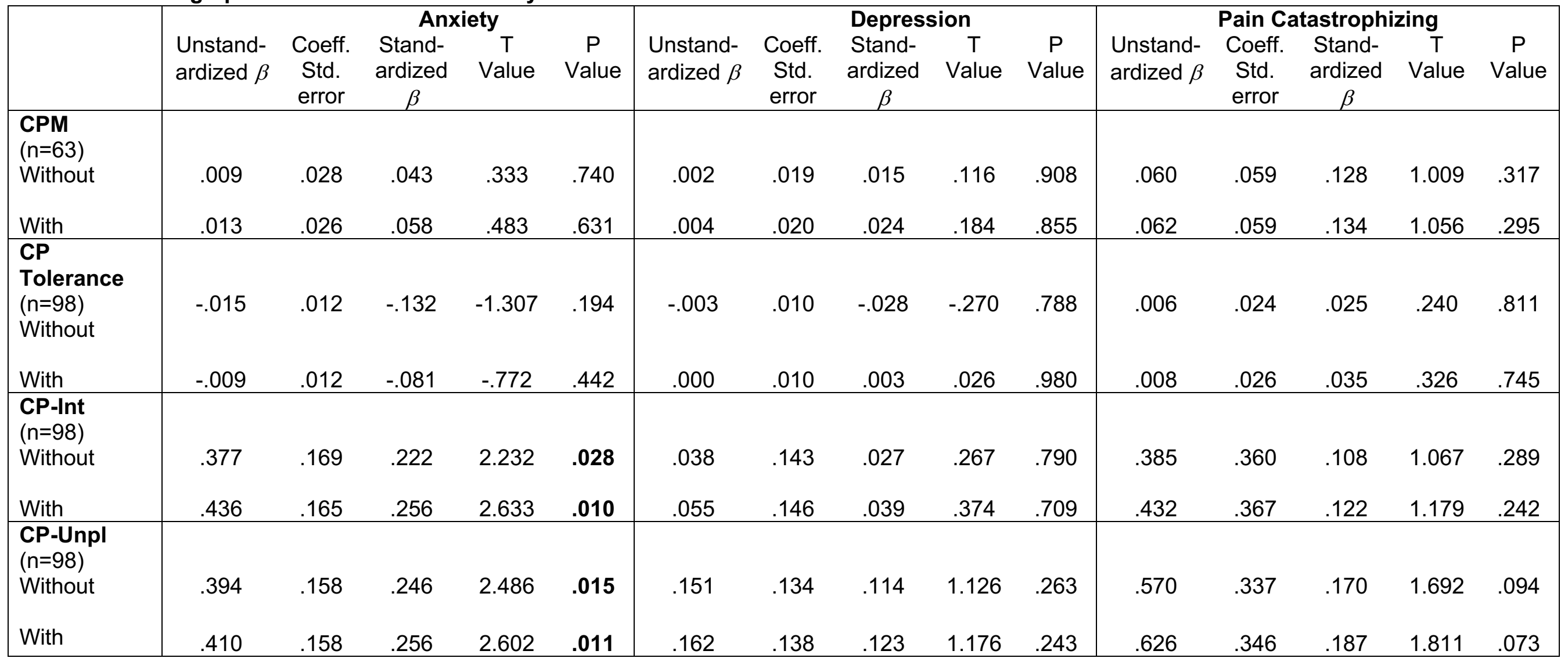

CPM, Conditioned Pain Modulation Response; CP Tolerance, Cold Pain Tolerance; CP-Int, Cold Pain Intensity Ratings; CP-Unpl, Cold Pain Unpleasantness Ratings. 
Table 7. Relationships between psychological factors and experimental pain sensitivity with and without controlling for demographic factors- Results of Study \#6

\begin{tabular}{|c|c|c|c|c|c|c|c|c|c|c|c|c|c|c|c|}
\hline & \multicolumn{5}{|c|}{ Anxiety } & \multicolumn{5}{|c|}{ Depression } & \multicolumn{5}{|c|}{ Pain Catastrophizing } \\
\hline & $\begin{array}{l}\text { Unstand- } \\
\text { ardized } \beta\end{array}$ & $\begin{array}{l}\text { Coeff. } \\
\text { Std. } \\
\text { error }\end{array}$ & $\begin{array}{c}\text { Stand- } \\
\text { ardized } \\
\beta\end{array}$ & $\begin{array}{c}\mathrm{T} \\
\text { Value }\end{array}$ & $\begin{array}{c}P \\
\text { Value }\end{array}$ & $\begin{array}{l}\text { Unstand- } \\
\text { ardized } \beta\end{array}$ & $\begin{array}{l}\text { Coeff. } \\
\text { Std. } \\
\text { error }\end{array}$ & $\begin{array}{c}\text { Stand- } \\
\text { ardized } \\
\beta\end{array}$ & $\begin{array}{c}\mathrm{T} \\
\text { Value }\end{array}$ & $\begin{array}{c}\mathrm{P} \\
\text { Value }\end{array}$ & $\begin{array}{l}\text { Unstand- } \\
\text { ardized } \beta\end{array}$ & $\begin{array}{l}\text { Coeff. } \\
\text { Std. } \\
\text { error }\end{array}$ & $\begin{array}{c}\text { Stand- } \\
\text { ardized } \\
\beta\end{array}$ & $\begin{array}{c}\mathrm{T} \\
\text { Value }\end{array}$ & $\begin{array}{c}P \\
\text { Value }\end{array}$ \\
\hline $\begin{array}{l}\text { PPT } \\
(n=21)\end{array}$ & & & & & & & & & & & & & & & \\
\hline Without & -.012 & .011 & -.243 & -1.093 & .288 & -.011 & .008 & -.315 & -1.445 & .165 & -.020 & .013 & -.333 & -1.537 & .141 \\
\hline With & -.008 & .019 & -.154 & -.416 & .683 & -.002 & .006 & -.056 & -.319 & .755 & -.019 & .022 & -.307 & -.862 & .403 \\
\hline
\end{tabular}

PPT, Pressure Pain Threshold. 
Table 8. Relationships between psychological factors and experimental pain sensitivity with and without controlling for demographic factors- Results of Study \#7

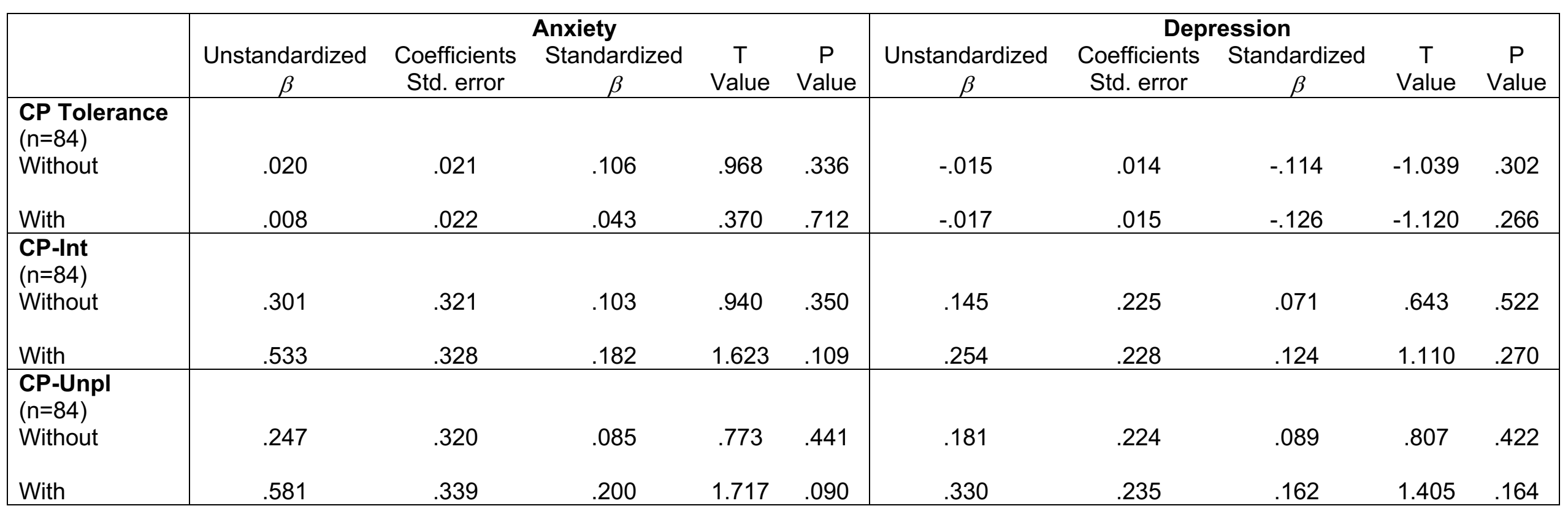

CP Tolerance, Cold Pain Tolerance; CP-Int, Cold Pain Intensity Ratings; CP-Unpl, Cold Pain Unpleasantness Ratings. 
Table 9. Relationships between psychological factors and experimental pain sensitivity with and without controlling for demographic factors- Results of Study \#8

\begin{tabular}{|l|ccccc|}
\hline & \multicolumn{5}{|c|}{ Pain Catastrophizing Scale } \\
& $\begin{array}{c}\text { Unstandardized } \\
\beta\end{array}$ & $\begin{array}{c}\text { Coefficients } \\
\text { Std. error }\end{array}$ & $\begin{array}{c}\text { Standardized } \\
\beta\end{array}$ & $\begin{array}{c}\mathrm{T} \\
\text { Value }\end{array}$ & $\begin{array}{c}\mathrm{P} \\
\text { Value }\end{array}$ \\
\hline $\begin{array}{l}\text { PPT } \\
\text { (n=224) }\end{array}$ & & & & & \\
Without & -.013 & .007 & -.122 & -1.828 & .069 \\
With & -.012 & .007 & -.110 & -1.715 & .088 \\
\hline $\begin{array}{l}\text { CPM } \\
\text { (n=105) }\end{array}$ & & & & & \\
Without & .010 & .014 & .067 & .681 & .498 \\
With & .009 & .014 & .062 & .662 & .510 \\
\hline $\begin{array}{l}\text { CP-Int } \\
\text { (n=91) }\end{array}$ & & & & & \\
Without & .590 & .405 & .153 & 1.457 & .149 \\
With & .449 & .402 & .116 & 1.117 & .267 \\
\hline
\end{tabular}

PPT, Pressure Pain Thresholds; CPM, Conditioned Pain Modulation Response; CP-Int, Cold Pain Intensity Ratings. 
Table 10. Summary of aggregate analyses.

\begin{tabular}{|c|c|c|c|c|c|c|c|c|c|}
\hline $\begin{array}{l}\text { Psychological } \\
\text { Factors }\end{array}$ & $\begin{array}{c}\text { Pain } \\
\text { Modalities }\end{array}$ & $\begin{array}{l}\text { No. Included } \\
\text { Studies (n } \\
\text { participants) }\end{array}$ & $\begin{array}{c}P \text { - } \\
\text { value }\end{array}$ & $T^{2}$ & $\mathbf{T}$ & $R(\%)$ & $H^{2}$ & $\begin{array}{l}\text { Cochran's Q Test } \\
\text { for Heterogeneity }\end{array}$ & $\begin{array}{c}\text { Grand Mean } \\
\text { Correlation r }(95 \% \\
\mathrm{Cl}) \text { in Original } \\
\text { Units }\end{array}$ \\
\hline \multirow{5}{*}{$\frac{\substack{\frac{1}{0} \\
\frac{1}{x}}}{\frac{1}{4}}$} & PPT & 5 (129) & 0.033 & $\begin{array}{c}0 \\
(\mathrm{SE}=0.0255)\end{array}$ & 0 & 0.00 & 1.00 & $\begin{array}{c}Q(d f=4)=0.5897 \\
p=0.9642\end{array}$ & $\begin{array}{c}r=-0.1010 \\
(-0.1873 \text { to }- \\
0.0131)\end{array}$ \\
\hline & CPM & 7 (197) & 0.804 & $\begin{array}{c}0.0128 \\
(\mathrm{SE}=0.0235)\end{array}$ & 0.1132 & 31.69 & 1.46 & $\begin{array}{c}Q(d f=6)=8.7831 \\
p=0.1861\end{array}$ & $\begin{array}{c}r=-0.0207 \\
(-0.2121 \text { to } 0.1723)\end{array}$ \\
\hline & $\begin{array}{l}\text { Cold Pain } \\
\text { Tolerance }\end{array}$ & $3(213)$ & 0.720 & $\begin{array}{c}0.0205 \\
(S E=0.0376)\end{array}$ & 0.1430 & 55.86 & 2.27 & $\begin{array}{c}Q(d f=2)=4.5310 \\
p=0.1038\end{array}$ & $\begin{array}{c}r=0.0461 \\
(-0.4094 \text { to } 0.4832)\end{array}$ \\
\hline & $\begin{array}{l}\text { Cold Pain } \\
\text { Intensity }\end{array}$ & $6(321)$ & 0.021 & $(\mathrm{SE}=0.0134)$ & 0 & 0.00 & 1.00 & $\begin{array}{c}Q(d f=5)=4.5980 \\
p=0.4669\end{array}$ & $\begin{array}{c}r=0.1810 \\
(0.0413 \text { to } 0.3137)\end{array}$ \\
\hline & $\begin{array}{c}\text { Cold Pain } \\
\text { Unpleasant } \\
\text { ness }\end{array}$ & $6(321)$ & 0.068 & $\begin{array}{c}0.0070 \\
(\mathrm{SE}=0.0180)\end{array}$ & 0.0836 & 24.82 & 1.33 & $\begin{array}{c}Q(d f=5)=6.6503 \\
p=0.2480\end{array}$ & $\begin{array}{c}r=0.1618 \\
(-0.0180 \text { to } 0.3315)\end{array}$ \\
\hline \multirow{5}{*}{ 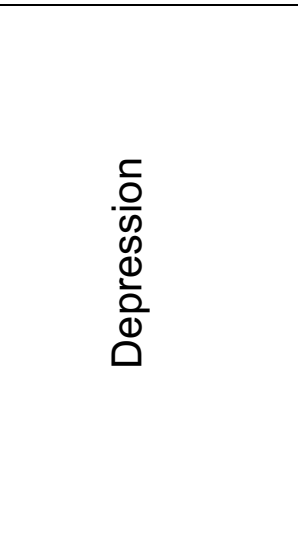 } & PPT & 5 (129) & 0.571 & $\begin{array}{c}0 \\
(\mathrm{SE}=0.0255)\end{array}$ & 0 & 0.00 & 1.00 & $\begin{array}{c}Q(d f=4)=2.7271 \\
p=0.6045\end{array}$ & $\begin{array}{c}r=-0.0422 \\
(-0.2278 \text { to } 0.1465)\end{array}$ \\
\hline & CPM & 7 (197) & 0.274 & $\begin{array}{c}0 \\
(\mathrm{SE}=0.0159)\end{array}$ & 0 & 0.00 & 1.00 & $\begin{array}{c}Q(d f=6)=1.8926 \\
p=0.9293\end{array}$ & $\begin{array}{c}r=-0.0418 \\
(-0.1263 \text { to } 0.0432)\end{array}$ \\
\hline & $\begin{array}{l}\text { Cold Pain } \\
\text { Tolerance }\end{array}$ & $3(213)$ & 0.136 & $\begin{array}{c}0 \\
(\mathrm{SE}=0.0162)\end{array}$ & 0 & 0.00 & 1.00 & $\begin{array}{c}Q(d f=2)=0.3292 \\
p=0.8482\end{array}$ & $\begin{array}{c}r=-0.0690 \\
(-0.1890 \text { to } 0.0531)\end{array}$ \\
\hline & $\begin{array}{l}\text { Cold Pain } \\
\text { Intensity }\end{array}$ & $6(321)$ & 0.217 & $\begin{array}{c}0.0020 \\
(\mathrm{SE}=0.0147)\end{array}$ & 0.0443 & 8.47 & 1.09 & $\begin{array}{c}Q(d f=5)=5.4629 \\
p=0.3620\end{array}$ & $\begin{array}{c}r=0.0860 \\
(-0.0706 \text { to } 0.2384)\end{array}$ \\
\hline & $\begin{array}{c}\text { Cold Pain } \\
\text { Unpleasant } \\
\text { ness }\end{array}$ & $6(321)$ & 0.068 & $\begin{array}{c}0 \\
(\mathrm{SE}=0.0134)\end{array}$ & 0 & 0.00 & 1.00 & $\begin{array}{c}Q(d f=5)=3.4236 \\
p=0.6350\end{array}$ & $\begin{array}{c}r=0.1099 \\
(-0.0119 \text { to } 0.2284)\end{array}$ \\
\hline \multirow{3}{*}{ 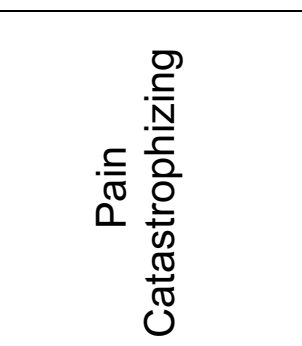 } & PPT & $4(277)$ & 0.036 & $\begin{array}{c}0 \\
(\mathrm{SE}=0.0195)\end{array}$ & 0 & 0.00 & 1.00 & $\begin{array}{c}Q(d f=3)=1.3262 \\
p=0.7229\end{array}$ & $\begin{array}{c}r=-0.1397 \\
(-0.2574 \text { to }- \\
0.0178)\end{array}$ \\
\hline & CPM & $4(200)$ & 0.319 & $\begin{array}{c}0 \\
(\mathrm{SE}=0.0165)\end{array}$ & 0 & 0.00 & 1.00 & $\begin{array}{c}Q(d f=3)=1.6899 \\
p=0.6392\end{array}$ & $\begin{array}{c}r=0.0602 \\
(-0.1004 \text { to } 0.2178)\end{array}$ \\
\hline & $\begin{array}{l}\text { Cold Pain } \\
\text { Intensity }\end{array}$ & $3(221)$ & 0.171 & $\begin{array}{c}0 \\
(\mathrm{SE}=0.0155)\end{array}$ & 0 & 0.00 & 1.00 & $\begin{array}{c}Q(d f=2)=1.0431 \\
p=0.5936\end{array}$ & $\begin{array}{c}r=0.1035 \\
(-0.1091 \text { to } 0.3070)\end{array}$ \\
\hline
\end{tabular}

PPT indicates pressure pain threshold; CPM indicates conditioned pain modulation; $\mathrm{H}^{2}$ : total variability/within-study variance; $I^{2}: \%$ of total variability due to heterogeneity; $\mathrm{T}$ : square root of $\mathrm{T}^{2} ; \mathrm{T}^{2}$ : estimate of the total amount of heterogeneity. 


\section{Supplementary 1- Methods for the Specific Studies}

\section{Study 1}

This study was conducted in healthy adolescents at Cincinnati Children's Hospital. One female investigator and two male investigators conducted this study. Full procedures for this study are described in ${ }^{1}$.

\section{Participants}

Study inclusion criteria: 1) age 12-17, 2) no chronic pain disorders, 3) no psychiatric or neurological (except for attention deficit disorder) disorders, 4) not taking medications on a regular basis (except oral contraceptives). This study was approved by the Institutional Review Board of Cincinnati Children's Hospital Medical Center. Written, informed consent was obtained from all participants' parent or guardian prior to participating in the study, and assent was obtained from all participants prior to participating in the study.

\section{Psychological Questionnaires}

Participants completed The Patient-Reported Outcomes Measurement Information System (PROMIS $尺$ ) adolescent anxiety and depression instruments.

\section{Quantitative Sensory Testing}

Pressure Pain Threshold-Pressure Pain Threshold was delivered with a pressure algometer $(1 \mathrm{~cm}$ diameter probe, Medoc, Israel), to the lower dominant leg (tibialis anterior muscle). The increase rate was 60 kilopascal $(\mathrm{kPa})$. The participants were instructed to press a button once the sensation of pain was experienced, and the force at the pain threshold was recorded. 
Conditioned Pain Modulation - Two CPM paradigms were collected. The paradigms differed in the modality of the test stimulus. Since CPM responses evoked using different test stimulus measures do not correlate with each other and may represent different inhibitory mechanisms ${ }^{1,2}$, we included both CPM results.

The test stimuli were 1) tonic heat stimulus (delivered to the lower dominant leg for 30 seconds at an intensity of $46.0^{\circ} \mathrm{C}$ ), and 2) pressure pain thresholds. The conditioning stimulus was cold-water immersion of the non-dominant foot into a cold-water bath $\left(8^{\circ} \mathrm{C}\right)$ for 60 seconds. The test stimuli were delivered alone and then concurrently with the conditioning stimulus. The CPM was repeated three times. For this analysis, only the first CPM repetition from each paradigm was included.

Pain ratings of cold-water immersion- Participants rated pain intensity and pain unpleasantness from the conditioning stimulus after 20 seconds of immersion using a mechanical visual analog scale (VAS).

\section{Study 2}

This study was conducted in healthy adolescents at Cincinnati Children's Hospital. One female investigator conducted this study's visits. Full procedures for this study are described in ${ }^{3}$.

\section{$\underline{\text { Participants }}$}

Study inclusion criteria: 1) age 10-17 years old; 2) no chronic pain disorders; 3) no current use of opioids, antipsychotics, antimanic, barbiturates, benzodiazepines, muscle relaxants, sedatives, tramadol, nutraceuticals, SSRIs, SSNRIs; 4) no neurological or psychiatric diseases; and 5) not pregnant. Informed parental permission and participant 
assent were obtained before study procedures began. The study was approved by the Cincinnati Children's Hospital Institutional Review Board (IRB).

\section{Psychological Questionnaires}

Participants completed the anxiety and depression adolescent instruments of The Patient-Reported Outcomes Measurement Information System (PROMIS®).

\section{Quantitative sensory testing}

Pressure pain threshold- Pressure was delivered to the trapezius with a pressure algometer ( $1 \mathrm{~cm}$ diameter probe, Medoc, Israel). The pressure from the algometer was increased at a rate of 60 kilopascals $(\mathrm{kPa})$ per second until the participant felt the first sensation of pain (i.e., threshold). Once the sensation of pain was experienced, the participants were instructed to press a button (at which time the pressure was removed from the trapezius), and the force applied at pain threshold was recorded (using $\mathrm{kPa}$ ). CPM- CPM paradigm was examined using pressure pain thresholds as the test stimulus and cold-water immersion for the conditioning stimulus. Participants were instructed to immerse their non-dominant foot into a cold-water bath $\left(8^{\circ} \mathrm{C}\right)$ for up to 60 seconds. Pressure pain thresholds was delivered alone and concurrently during the last 30 seconds of the conditioning stimulus.

Pain ratings of cold-water immersion- Participants rated pain intensity and unpleasantness from this stimulus after 20 seconds of immersion using a VAS.

\section{Study 3}

This study was conducted in healthy adolescents at Cincinnati Children's Hospital. One male investigator and one female investigator conducted this study's visits. 


\section{$\underline{\text { Participants }}$}

Study inclusion criteria: 1) age range between 12-17, 2) not diagnosed with autoimmune disease, 3) no current cold or flu symptoms, 4) no uncontrolled diabetes, 5) no recent surgery or injury requiring hospitalization ( $<6$ weeks), 6 ) no developmental delays, neurological disorders or uncontrolled psychological disorders, 7) no use of opioids, and 8) no diagnosed pain conditions. Cincinnati Children's Hospital Medical Center Institutional Review Board approved all study procedures. Parents or guardians of participants gave written informed consent, and participants gave assent stating they understood that they would experience pressure and cold stimuli, that the experimental procedures were clearly explained, and that they could withdraw at any time without prejudice.

\section{Psychological Questionnaires}

Participants completed the PROMIS Anxiety measure for adolescents and PROMIS Depression measure for adolescents, as well as the Pain Catastrophizing Scale for Children (PCS-C).

\section{Quantitative Sensory Testing}

Pressure Pain Thresholds-Two PPT trials were completed at the forearm or the trapezius in a counterbalanced order: forearm first for participants with an even ID number and trapezius trials first for participants with odd ID number. Participants were asked to press a button and say the word "pain" out loud when they first experienced a painful sensation from the pressure. In each trial there were three PPT repetitions. The PPT value was based on the average of the last two repetitions. 
Conditioned Pain Modulation - Two CPM paradigms were collected. The paradigms differed in the location of the test stimulus. Since CPM responses evoked using different test stimulus measures do not correlate with each other and may represent different inhibitory mechanisms ${ }^{1,2}$, we included both CPM results.

The test stimuli were 1) PPT at the forearm and 2) PPT at the trapezius. The conditioning stimulus was cold-water immersion in which participants submerged their dominant hands in a circulating water bath $\left(10^{\circ} \mathrm{C}\right)$ up to wrist level for a total submersion time of around 60 seconds. In order to prevent a boundary layer of warmth from forming around the hand, participants were asked to keep their fingers spread apart while in the water.

Pain ratings of cold-water immersion- The Cold Pressor test was performed twice (for the two CPM paradigms). For the current analyses, pain ratings from only the first Cold Pressor test were included. After 20 seconds of submersion, participants provided a rating of cold pain intensity and unpleasantness on a Visual Analogue Scale.

\section{Study 4}

This study was conducted in healthy adults at Cincinnati Children's Hospital. One male investigator and two female investigators conducted this study's visits.

\section{$\underline{\text { Participants }}$}

Study inclusion criteria: 1) age 14-44, 2) good general health, 3) able to undergo an MRI scan, 4) no psychiatric or neurological conditions, 5) no medications which may alter pain sensitivity or brain activity, 6) not pregnant, 7) no history of chronic pain conditions, 8) not diabetic, 9) no skin conditions/damage on arms or legs near sites of sensory 
testing. This study was approved by the Institutional Review Board of Cincinnati Children's Hospital Medical Center. Written, informed consent was obtained from all adult participants, and for the one adolescent in the study the participants' parent or guardian provided consent and the adolescents provided assent.

\section{Psychological Questionnaires}

Participants completed the Spielberger State-Trait Anxiety Inventory and Beck Depression Inventory-II.

\section{Quantitative Sensory Testing}

Cold pain tolerance- Assessed by having participants immerse one hand in a cold $\left(4^{\circ} \mathrm{C}\right)$ water bath. Tolerance was defined by the time of hand withdrawal. VAS ratings of pain intensity and pain unpleasantness were recorded upon hand withdrawal. Limb immersion in the cold-water bath was terminated after 120 seconds if participants did not withdraw their hand before then.

Conditioned Pain Modulation - The test stimulus was a tonic heat stimulus delivered to the ventral forearm for 30 seconds at an intensity of $48.0^{\circ} \mathrm{C}$. Real time pain intensity ratings were obtained using a computerized VAS. The conditioning stimulus was immersion of the foot into a cold-water bath $\left(8^{\circ} \mathrm{C}\right)$ for 60 seconds. The test stimulus was delivered alone and then concurrently with the conditioning stimulus.

Pain ratings of cold-water immersion-VAS ratings of pain intensity and pain unpleasantness were recorded at the end of the cold pain tolerance test and upon hand withdrawal. 


\section{Study 5}

This study was conducted in healthy adults at Cincinnati Children's Hospital. Three male investigator and two female investigators conducted this study's visits.

\section{Participants}

Study inclusion criteria: 1) age 14-44, 2) good general health, 3) able to undergo an MRI scan, 4) no psychiatric or neurological conditions, 5) no medications which may alter pain sensitivity or brain activity, 6) not pregnant, 7) no history of chronic pain conditions, 8) not diabetic, 9) no skin conditions/damage on arms or legs near sites of sensory testing. This study was approved by the Institutional Review Board of Cincinnati Children's Hospital Medical Center. Written, informed consent was obtained from all adult participants, and for the seven adolescents in the study the participants' parent or guardian provided consent and the adolescents provided assent.

\section{Psychological Questionnaires}

Participants completed The Patient-Reported Outcomes Measurement Information System (PROMIS $®$ ) adult or adolescent anxiety, depression, and Pain Catastrophizing Scale.

\section{Quantitative Sensory Testing}

Cold pain tolerance- Assessed by having participants immerse one hand in a cold $\left(4^{\circ} \mathrm{C}\right)$ water bath. Tolerance was be defined by the time of hand withdrawal. Limb immersion in the cold-water bath was terminated after 120 seconds if participants did not withdraw their hand before then.

Conditioned Pain Modulation - The test stimulus was a tonic heat stimulus delivered to the ventral forearm for 30 seconds at an intensity of $48.0^{\circ} \mathrm{C}$. Real time pain intensity 
ratings were obtained using a computerized visual analog scale, which ranges between "no pain sensation" and "most intense pain imaginable". The conditioning stimulus was immersion of the foot into a cold-water bath $\left(8^{\circ} \mathrm{C}\right)$ for 60 seconds. The test stimulus was delivered alone and then concurrently with the conditioning stimulus.

Pain ratings of cold-water immersion-VAS ratings of pain intensity and pain unpleasantness were recorded at the end of the cold pain tolerance test and upon hand withdrawal.

\section{Study 6}

This study was conducted in healthy adults at Cincinnati Children's Hospital. One male investigator conducted this study's visits. Full procedures for this study are described in 4.

\section{Participants}

Participants were recruited from Cincinnati Children's Hospital and the surrounding area using print and social media. Study inclusion criteria were: 1) age 18-50, 2) Englishspeaking, 3) no cancer treatment in the past year, 4) not diagnosed with or in current treatment for diabetes, thyroid disorder, cardiovascular disorder, hypertension, pulmonary disease, or neurological disorder, 5) no psychiatric disorder requiring hospitalization in the past year, 6) not pregnant, 7) not using opioids, and 8) no hospitalizations or surgeries in the last 6 months. This study was approved by the Institutional Review Board at Cincinnati Children's Hospital Medical Center.

\section{Psychological Questionnaires}


Participants completed the PROMIS depression, PROMIS anxiety, and Pain Catastrophizing Scale.

Quantitative Sensory Testing

Pressure Pain Threshold-Pressure was delivered with a pressure algometer $(1 \mathrm{~cm}$ diameter probe, Medoc, Israel), which was delivered to the forearm. The pressure from the algometer was gradually increased until the participant felt the first sensation of pain (e.g., threshold). Once the sensation of pain was experienced, the participants were instructed to press a button, and the force applied at pain threshold was recorded (using $\mathrm{kPa})$.

\section{Study 7}

This study was conducted in healthy adults at Wake Forest University School of Medicine. One female investigator conducted this study's visits.

\section{Participants}

Study inclusion criteria: 1) no history of chronic pain conditions, 2) no chronic disease conditions, diabetes, or psychiatric or neurological disorders, 3) no current medication use, 4) BMls $<25$ or $<29.9 \mathrm{~kg} / \mathrm{m}^{2}$. Participants gave written informed consent stating they understood that they would experience painful thermal stimulation, that the experimental procedures were clearly explained, and that they could withdraw at any time without prejudice. Wake Forest University School of Medicine Institutional Review Board approved all study procedures.

\section{Psychological Questionnaires}


Participants completed the Spielberger State-Trait Anxiety Inventory and Beck Depression Inventory-II.

\section{Quantitative sensory testing}

Cold pain tolerance- Participants submerged their left hands in an ice water bath (0$2^{\circ} \mathrm{C}$ ) up to wrist level for 120 seconds or until pain tolerance occurred. In order to promote circulation and prevent a boundary layer of warmth from forming around the hand, participants were instructed to continuously open and close their hands for the duration of the test. In addition, participants were instructed to notify the experimenter when they first felt pain and to remove their hand when they could no longer tolerate the pain. The duration of submersion before the participant removed their hand was recorded as tolerance.

Pain ratings of cold-water immersion-VAS ratings of pain intensity and unpleasantness were collected at termination of the cold pain tolerance test.

\section{Study 8}

This study was conducted in healthy adults at the University of Kentucky. One male investigator conducted this study's visits. Full procedures for this study are described in 5 .

\section{$\underline{\text { Participants }}$}

Participants were recruited from the undergraduate population at the University of Kentucky using the psychology subject pool which assigns course credits for participating in research. Study inclusion criteria: 1) age 18 or older, 2) no history of chronic pain disorders, 3) no neurodegenerative, stroke, psychiatric, or neurological 
disorders, 4) no current psychotropic, statin, blood pressure or pain medication, including over-the-counter pain medications in the past 24 hrs., and 5) no current pain (i.e., answer of 0 on a $0-5$ scale to the question of current pain). This study was approved by the Institutional Review Board at the University of Kentucky. Participants provided signed informed consent before participating in the study.

\section{Psychological Questionnaires}

Participants completed the Pain Catastrophizing Scale.

\section{Quantitative Sensory Testing}

Pressure Pain Threshold Ratings - An experimenter placed the participant's intermediate phalange of the ring finger of their nondominant hand in a pressure algometer with a $1 \mathrm{~cm}$ diameter tip and applied pressure at a steady rate of approximately $30 \mathrm{kPA} / \mathrm{sec}$. Participants were given a trigger to hold in their dominant hand and were instructed to press the trigger when the pressure first turned to pain. Three consecutive ratings spaced $5 \mathrm{sec}$ apart were taken for each participant and averaged to improve reliability.

Conditioned Pain Modulation - A subset of the sample ( $N=91$ with complete psychological and pain data) were asked to additionally complete a conditioned pain modulation test. The test stimulus was pressure pain threshold and the conditioning stimulus was cold water immersion. Participants were asked to place their nondominant foot in a circulating ice bath of $4.4^{\circ} \mathrm{C}$ water. After 20 seconds of their foot being in the water, they provided three additional pressure pain thresholds using the procedures described above. 
Pain ratings of cold-water immersion-Participants were asked to rate their pain intensity using verbal numerical pain scale at the end of the conditioning stimulus.

\section{References}

1. Nahman-Averbuch H, Leon E, Hunter BM, et al. Increased pain sensitivity but normal pain modulation in adolescents with migraine. Pain 2019.

2. Nahman-Averbuch H, Yarnitsky D, Granovsky G, Gerber E, Dagul P, Granot M. The role of stimulation parameters on 'conditioned pain modulation' response. Scandinavian Journal of Pain 2013;4:10-14.

3. Nahman-Averbuch H, Thomas PL, Schneider VJ, 2nd, et al. Spatial aspects of pain modulation are not disrupted in adolescents with migraine. Headache 2020.

4. Boggero IA, Schneider VJ, 2nd, Thomas PL, Nahman-Averbuch H, King CD. Associations of self-report and actigraphy sleep measures with experimental pain outcomes in patients with temporomandibular disorder and healthy controls. Journal of psychosomatic research 2019;123:109730.

5. Boggero IA, Segerstrom SC. Self-regulatory ability, fatigue, and the experience of pain: Mechanistic insights from pain-free undergraduates. Psychophysiology 2019;56:e13388. 
Anxiety

Depression
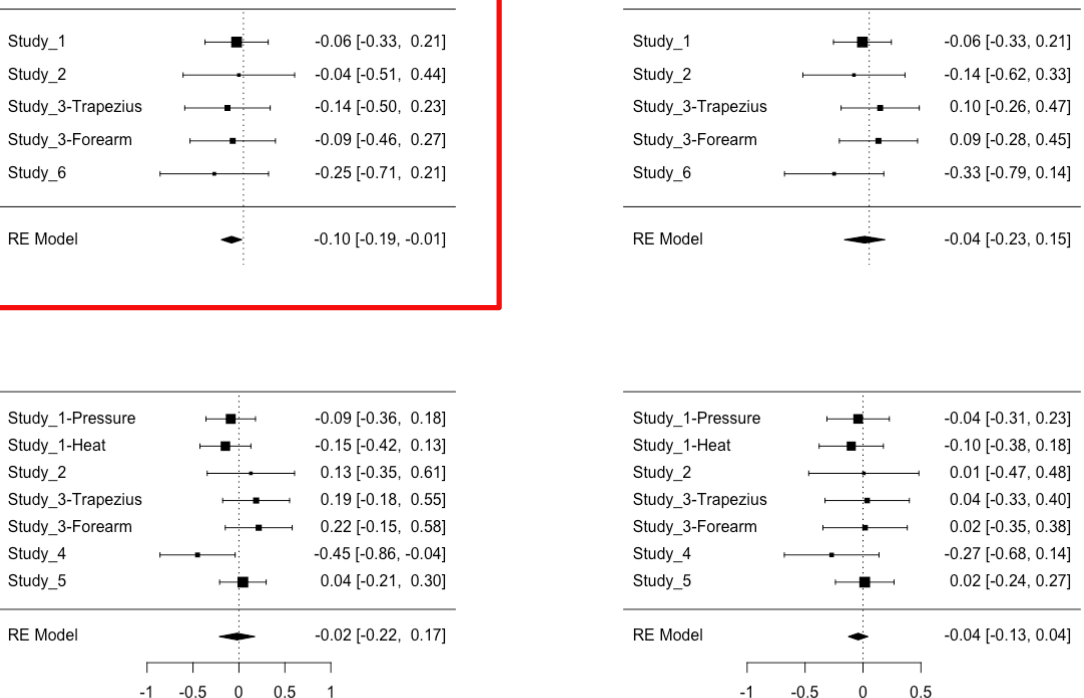

$\frac{0}{\frac{0}{\sigma}}$

$\frac{\sum}{0}$

$\frac{1}{n}$

\begin{tabular}{lll}
\hline Study_1 & $-0.06[-0.33,0.21]$ \\
Study_2 & - & $\begin{array}{l}-0.04[-0.51,0.44] \\
-0.14[-0.50,0.23] \\
\text { Study_3-Trapezius }\end{array}$ \\
Study_3-Forearm & $-0.09[-0.46,0.27]$ \\
Study_6 & $-0.25[-0.71,0.21]$ \\
\hline RE Model & - & $-0.10[-0.19,-0.01]$
\end{tabular}

RE Model

$-0.10[-0.19,-0.01]$

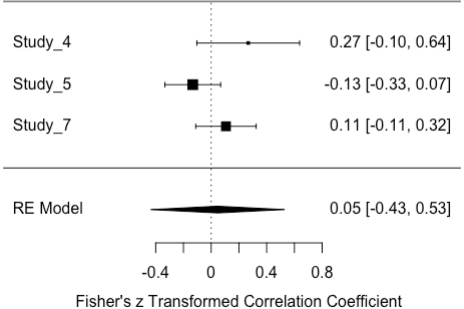

Fisher's z Transformed Correlation Coefficient

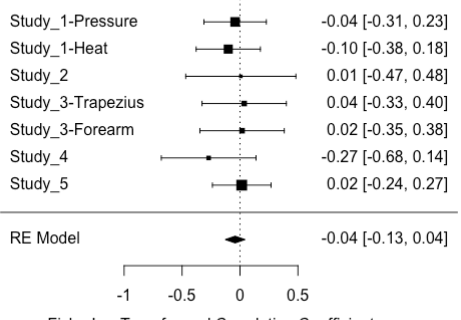

Fisher's z Transformed Correlation Coefficient

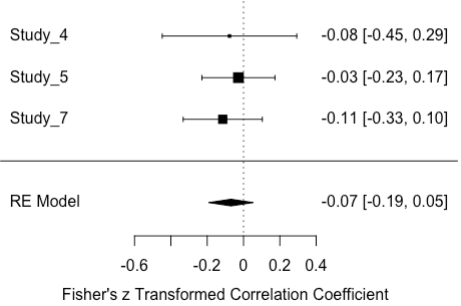

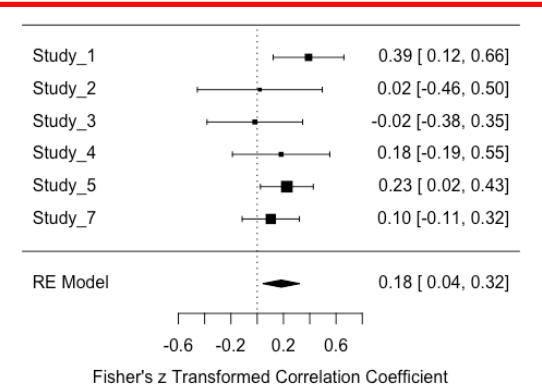

Fisher's z Transformed Correlation Coefficient

\begin{tabular}{lll} 
Study_3-Trapezius & \\
Study_3-Forearm & $-0.05[-0.42,0.31]$ \\
Study_6 & $-0.24[-0.60,0.13]$ \\
Study_8 & $-0.35[-0.81,0.12]$ \\
\hline RE Model & $-0.12[-0.25,0.01]$ \\
\hline
\end{tabular}

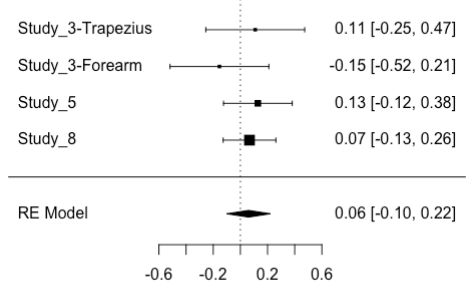

Fisher's z Transformed Correlation Coefficient

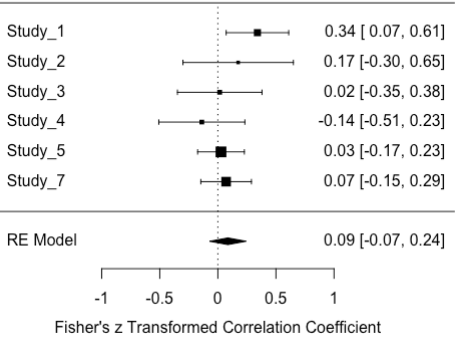

Fisher's z Transformed Correlation Coefficient

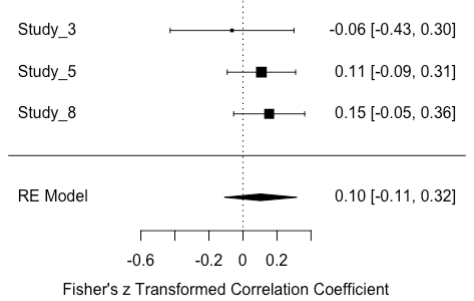

Fisher's z Transformed Correlation Coefficient

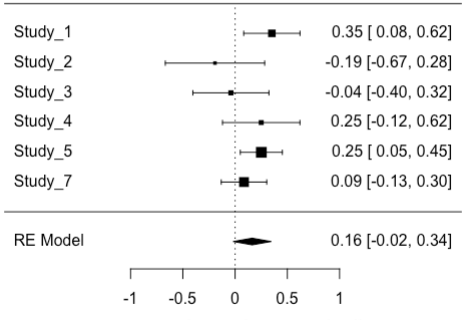

Fisher's z Transformed Correlation Coefficient

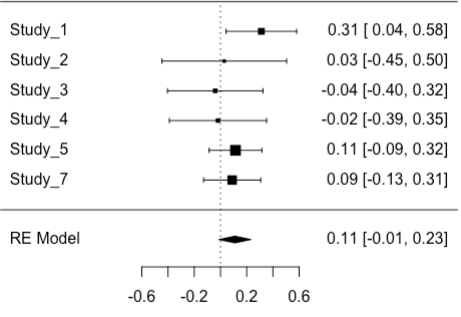

Fisher's z Transformed Correlation Coefficient 